\title{
Chemistry, gelation, and enzymatic modification of seaweed food hydrocolloids
}

\section{Rhein-Knudsen, Nanna; Meyer, Anne S.}

\section{Published in:}

Trends in Food Science and Technology

Link to article, DOI:

10.1016/j.tifs.2021.01.052

Publication date:

2021

Document Version

Peer reviewed version

Link back to DTU Orbit

Citation (APA):

Rhein-Knudsen, N., \& Meyer, A. S. (2021). Chemistry, gelation, and enzymatic modification of seaweed food hydrocolloids. Trends in Food Science and Technology, 109, 608-621. https://doi.org/10.1016/j.tifs.2021.01.052

\section{General rights}

Copyright and moral rights for the publications made accessible in the public portal are retained by the authors and/or other copyright owners and it is a condition of accessing publications that users recognise and abide by the legal requirements associated with these rights.

- Users may download and print one copy of any publication from the public portal for the purpose of private study or research.

- You may not further distribute the material or use it for any profit-making activity or commercial gain

- You may freely distribute the URL identifying the publication in the public portal

If you believe that this document breaches copyright please contact us providing details, and we will remove access to the work immediately and investigate your claim 


\section{Journal Pre-proof}

Chemistry, gelation, and enzymatic modification of seaweed food hydrocolloids

Nanna Rhein-Knudsen, Anne S. Meyer

PII: S0924-2244(21)00052-2

DOI: $\quad$ https://doi.org/10.1016/j.tifs.2021.01.052

Reference: TIFS 3130

To appear in: Trends in Food Science \& Technology

Received Date: 2 June 2020

Revised Date: 16 January 2021

Accepted Date: 22 January 2021

Please cite this article as: Rhein-Knudsen, N., Meyer, A.S., Chemistry, gelation, and enzymatic modification of seaweed food hydrocolloids, Trends in Food Science \& Technology (2021), doi: https:// doi.org/10.1016/j.tifs.2021.01.052.

This is a PDF file of an article that has undergone enhancements after acceptance, such as the addition of a cover page and metadata, and formatting for readability, but it is not yet the definitive version of record. This version will undergo additional copyediting, typesetting and review before it is published in its final form, but we are providing this version to give early visibility of the article. Please note that, during the production process, errors may be discovered which could affect the content, and all legal disclaimers that apply to the journal pertain.

() 2021 Published by Elsevier Ltd. 
1 Chemistry, gelation, and enzymatic

2 modification of seaweed food hydrocolloids

3 Nanna Rhein-Knudsen, Anne S. Meyer*

4 Protein Chemistry and Enzyme Technology Section, DTU Bioengineering, Department of Biotechnology and

5 Biomedicine, Technical University of Denmark, Søltofts Plads 221, DK-2800 Kgs. Lyngby, Denmark.

$6 \quad$ *corresponding author: Email: asme@dtu.dk

\section{Abstract}

Background: Carrageenan, agar, and alginate are seaweed-derived carbohydrate hydrocolloids which are used as thickening and gelling agents in foods, pharma and biotechnology applications due to their unique gelation properties. These hydrocolloids are extracted commercially from a set of high-yielding, cultivated seaweeds (marine macroalgae). The seaweed type and biological and environmental factors during seaweed growth determine the chemical and rheological hydrocolloid properties. New insight into biosynthesis and microbial degradation of these seaweed-derived hydrocolloids includes discovery of unique enzymes that catalyze specific structural changes in the carbohydrate polymers which affect the hydrocolloid properties.

Scope and Approach: In this review we describe the intricate chemical structures, gelation mechanisms and biosynthesis routes of seaweed hydrocolloids. We provide an overview of novel enzymes and enzyme reactions that catalyze changes in these hydrocolloids, and discuss how this new enzyme knowledge may enable further technological advancements in processing and applications of seaweed hydrocolloids.

Key Findings and Conclusions: The red seaweeds from the genera Kappaphycus and Eucheuma are key commercial sources of carrageenan, species from the genera Gracilaria and Gelidium are the main sources of agar, and brown seaweeds from the genera Laminaria and Macrocystis are currently the main sources of alginate. Recent progress has advanced our understanding of enzymatic reactions involved in the biosynthesis and microbial degradation of these hydrocolloids and especially uncovered unique epimerase, desulfatase, and alginate lyase processes. This new knowledge provides a basis for rethinking the sources and extraction protocols of these hydrocolloids because such enzymes can catalyze distinct molecular changes to improve the physical properties of the hydrocolloids. 
Keywords: Carrageenans; agar; alginate; epimerase; desulfatase 
Marine macroalgae, notably edible red (phylum Rhodophyta) and brown seaweeds (phylum Ochrophyta, class Phaeophyceae) are important sources of unique carbohydrate-based hydrocolloids, i.e. carrageenans, agar and alginate, respectively. Due to their gelation properties these hydrocolloids are used in many valueadded applications in foods, pharma, and biotechnology. These hydrocolloids are considered as food additives, and are generally recognized as safe by the US Food and Drug Administration and the European Food Safety Authority, and they have the following E numbers in the European Union: refined carrageenan has E number E 407 (includes furcelleran), semi-refined carrageenan has E 407a, agar has E 406, and alginates have several E numbers as follows: E 400 (alginic acid), E 401 (sodium alginate), E 403 (ammonium alginate), E 404 (calcium alginate) and E 405 (propane-1,2-diol alginate). The safety of carrageenans in foods has been debated, but based on their safe use history, acute and chronic toxicology tests, carrageenans are recognized as safe both by the US Food and Drug Administration and the European Food Safety Authority (David et al., 2018). Carrageenans and agar are commercially extracted from certain red seaweeds of which the most important sources are carrageenophyte species from the genera Kappaphycus and Eucheuma (notably from Eucheuma cottonii) and agarophyte species from the genera Gracilaria and Gelidium (Porse \& Rudolph, 2017). Alginate is commercially extracted from brown seaweed species, most commonly from the genera Laminaria, Lessonia, and Macrocystis amongst others, but there seems to be large unused quantities of other alginate-containing seaweeds available for cultivation, e.g. Saccharina species (Porse \& Rudolph, 2017). Carrageenans, agar and alginate each constitute a major part of the cell wall in the respective seaweeds they come from along with cellulose, proteins, ions, and other polysaccharides (e.g. fucoidans in brown seaweeds), and are associated with osmotic and ionic regulation, and known to contribute to cell adhesion, physical integrity and immunity of the macroalgae (DeniaudBouët et al., 2014). Green seaweeds (phylum Chlorophyta) accumulate unique sulfated carbohydrates, namely ulvan and rhamnan sulfate, along with polysaccharides consisting of xylose, arabinose, galactose, and/or glucuronic acid. These polysaccharides have been reported to have a range of biological activities, but their viscosity-enhancing properties are low, and to our knowledge green seaweed carbohydrates are not used commercially as hydrocolloids.

Recent market research predicts that the Global market for hydrocolloids will grow to 11.8 billion US\$ by 2025 with an annual compound growth rate (CAGR) of 5\% (Market Research 2020); in addition to seaweed derived hydrocolloids, the food hydrocolloids market includes gelatin, pectin, guar gum, and microcrystalline cellulose. Based on 2015 data and a CAGR of 5\%, we estimate that current total sales value of carrageenans, agar, and alginate amount to 1.5 billion US\$ with carrageenan sales accounting for more than $50 \%$ of this value (Rhein-Knudsen, Ale, \& Meyer, 2015). Certain bacteria belonging to the genera 
Azotobacter and Pseudomonas can also produce alginate (which they use to produce a capsular gel and biofilm), but the bacterial alginate is acetylated and is not employed commercially.

\section{Chemical structures and commercial extraction procedures}

Seaweed hydrocolloid polysaccharides are built of unique carbohydrate monomer structures and consist of either sulfated, dehydrated galactopyranosyl moieties (carrageenans and agar) or uronic acids (alginate). The ability to form gels or viscous solutions depends on the composition and configuration of the polysaccharides. The basic configurations of the different seaweed hydrocolloids are well-defined, but particular structural details such as the extent of 3,6-anhydrogalactopyranosyls in carrageenans and agar and the balance between the uronic acid types in alginate vary with seaweed species, life-stage, season, growth site, and water depth.

\section{Carrageenans}

Carrageenans are linear polysaccharides composed of different types of repeating $\beta-1,4$ linked disaccharide D-galactopyranosyl units bound together by $\alpha-1,3$ linkages. In nature, many types of carrageenans exist which can be distinguished by the amount and position of sulfate ester modifications as well as the content of 3,6-anhydrogalactopyranosyls, unique to red seaweeds. The carrageenans of commercial interest are known as K-, L-, and $\lambda$-carrageenan (Fig. 1) (Usov \& Zelinsky, 2013).

The 3,6-anhydro-D-galactopyranosyl moieties are present in $\mathrm{k}$ - and t-carrageenan, while $\lambda$-carrageenan is composed solely of sulfated galactopyranosyl monomers (Fig. 1). Sulfate modifications are present on all the carrageenans where $\mathrm{k}$-carrageenan has one sulfate ester per dimer, while $\mathrm{L}$ - and $\lambda$-carrageenan have two and three sulfate substitutions per dimer, respectively (Fig. 1). The chemical structures described above represent simplified structures. In nature, carrageenans are inherently heterogeneous and contain stretches of their biosynthetic precursors; $\mu$-carrageenan for $\mathrm{k}$-carrageenan and $\mathrm{v}$-carrageenan for $\mathrm{L}$ carrageenan. These precursors contain D-galactopyranosyl 4-sulfate and D-galactopyranosyl 6-sulfate or Dgalactopyranosyl 2-6-sulfate but no 3,6-anhydro-D-galactopyranosyls (Usov \& Zelinsky, 2013). Adding further to the complexity of the carrageenans, $\mathrm{k} / \mathrm{l}$ hybrid carrageenans exist along with other carrageenans within the same seaweed. Carrageenans may thus contain different diads in the same molecule and different distributions of them depending on the life cycle stage of the seaweed, e.g. the red macroalgae Chondrus crispus, commonly known as Irish moss, typically has $\mathrm{k}$ - and l-carrageenan in the gametophytes (haploid multicellular life-stage) and $\lambda$-carrageenan in the sporophytes (diploid multicellular life-stage) (Collén et al., 2013). 

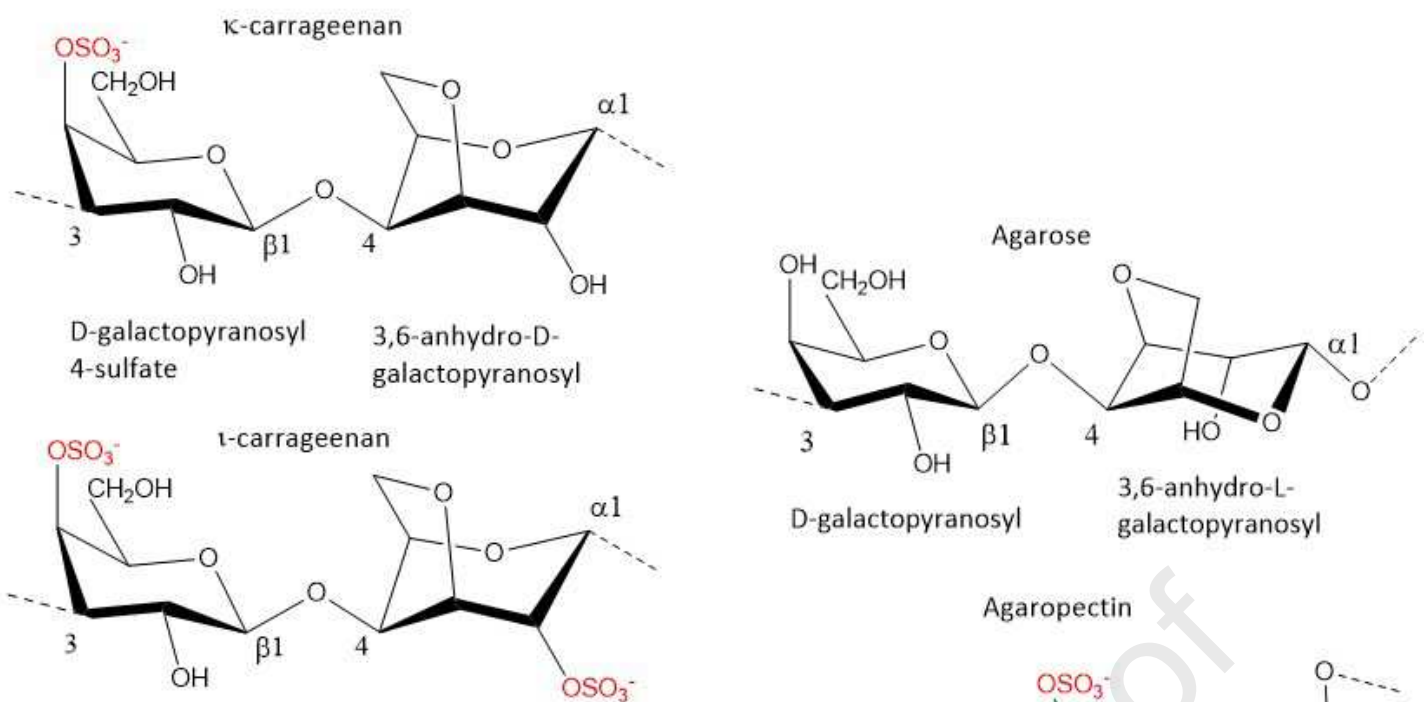

D-galactopyranosyl 3,6-anhydro-D-galacto4-sulfate pyranosyl 2-sulfate
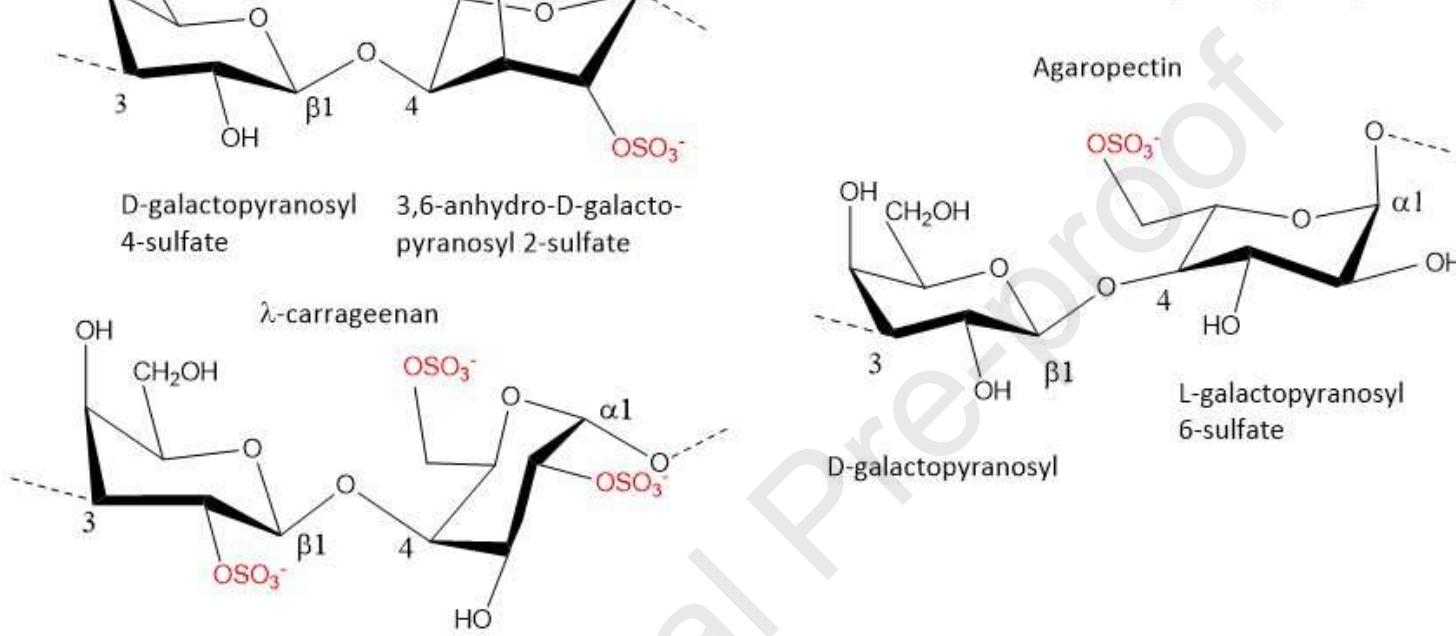

D-galactopyranosyl

D-galactopyranosyl D-galactopyranosyl 2-sulfate 2,6-sulfate

Fig. 1 Chemical structures of the three commercially used carrageenans, $\mathrm{K}_{-}, \mathrm{L}-$, and $\lambda$-carrageenan, and agarose and agaropectin, the constituents of agar.

The chemical structures together with the physical gelation properties form the basis for the currently used chemical extraction procedures which involve $\mathrm{pH}$ changes and use of cations to promote gelation. However, the extraction technique, i.e. water extraction or combined modification and extraction, may affect the chemical properties of the hydrocolloids. For production of high-value food and pharma carrageenans, the extraction protocol usually involves an alkali-treatment step (Table 1) by which the Dgalactopyranosyl 6-sulfates are converted into 3,6-anhydro-D-galactopyranosyls (typically by $\mathrm{KOH}$ for $\mathrm{k}$ carrageenan and $\mathrm{NaOH}$ for L-carrageenan) during the extraction (Istinii, Ohno, \& Kusunose, 1994).

The alkali induced modification mechanism converting D-galactopyranosyl 2,6-sulfate to 3,6-anhydro-Dgalactopyranosyl 2-sulfate, i.e. v-carrageenan to l-carrageenan (outlined in Fig. 2) was originally proposed by Ciancia et al. (1993). The reaction starts with ionization of the $\mathrm{C}_{3} \mathrm{OH}$ on the sulfated $\alpha$-galactopyranosyl residue, creating a charge repulsion between the ionized oxygen and the $C_{3}$ sulfate (Fig. 2). To situate these charged components as far away from each other as possible, the chair conformation changes from ${ }^{4} C_{1}$ to 
${ }^{1} \mathrm{C}_{4}$, arranging the charges in an axial position that enables an intramolecular $\mathrm{S}_{\mathrm{N}} 2$ reaction with the formation of the 3,6-anhydro ring and the concurrent displacement of the $\mathrm{C}_{6}$ sulfate group (Fig. 2). It is proposed that the analogous conversion of D-galactopyranosyl 6-sulfate to 3,6-anhydro-Dgalactopyranosyl, i.e. from the $\mu$-carrageenan precursor to $\mathrm{k}$-carrageenan (to be discussed later), occurs via an additional ionization of the $\mathrm{C}_{2} \mathrm{OH}$, which thus creates a similar repulsion effect. The conversion from ${ }^{4} \mathrm{C}_{1}$ to ${ }^{1} \mathrm{C}_{4}$ and notably the loss of a sulfate group and the 3,6-anhydro ring formation (Fig. 2) changes the hydrophobicity of the polysaccharides enabling helix induced gel formation (Ciancia, Noseda, Matulewicz, \& Cerezo, 1993).

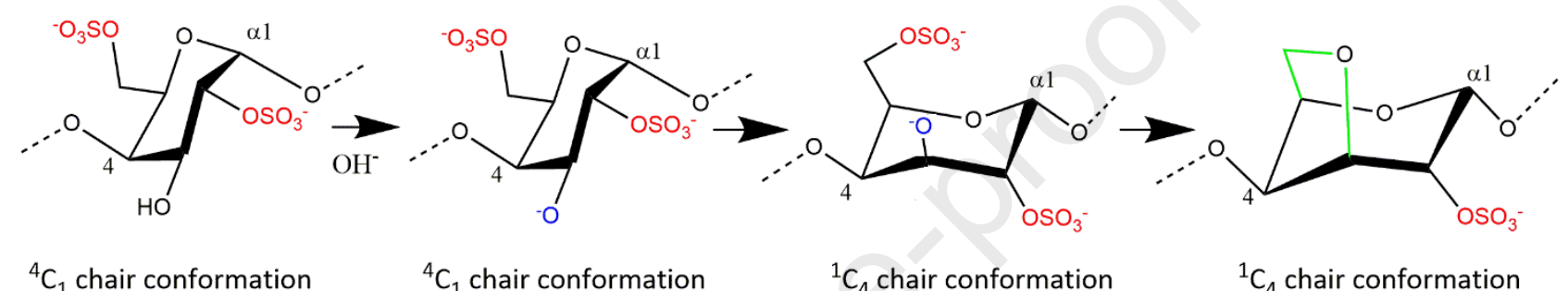

$C_{1}$ chair conformation

${ }^{4} \mathrm{C}_{1}$ chair conformation

${ }^{1} \mathrm{C}_{4}$ chair conformation

${ }^{1} \mathrm{C}_{4}$ chair conformation

Fig. 2 Proposed mechanism for alkali modification of D-galactopyranosyl 2,6-sulfate to 3,6-anhydro-Dgalactopyranosyl 2-sulfate, i.e. v-carrageenan to t-carrageenan.

Following modification, the carrageenans are extracted from the seaweeds in boiling water to minimize viscosity, separated from the seaweed residuals by filtration, and recovered by alcohol precipitation, outlined in Table 1. Native carrageenan, i.e. non-modified carrageenan, can be extracted directly in boiling water followed by filtration and alcohol precipitation. The exact reaction conditions vary between reported studies but generally carrageenans and agar are modified at $80-90{ }^{\circ} \mathrm{C}$ for $1-3$ hours, for carrageenans typically with $6 \% \mathrm{KOH}$ (for agar usually with 5-6 \% $\mathrm{NaOH}$ ), followed by washing and $\mathrm{pH}$ adjustment to prevent depolymerization, before they are extracted in boiling water for 1-3 hours (Table 1).

Table 1 Overview of processing steps and conditions for carrageenan, agar, and alginate extraction summarized from Istini et al., 1994 and Calumpong, Maypa, \& Magbanua, 1999.

\begin{tabular}{|c|c|c|c|}
\hline Process & Carrageenan extraction & Agar extraction & Alginate extraction \\
\hline Raw material & Drying, milling & Drying, milling & Drying, milling \\
\hline Alkali-modification & $\mathrm{KOH} / \mathrm{NaOH}, 80-90^{\circ} \mathrm{C}$ & $\mathrm{NaOH}, 80-90{ }^{\circ} \mathrm{C}$ & \\
\hline Phenolic compounds removal & & & Formaldehyde, $20^{\circ} \mathrm{C}$ \\
\hline Conversion to alginic acid & & & $\mathrm{HCl}$, room temp. \\
\hline Extraction & $\mathrm{H}_{2} \mathrm{O}, \mathrm{pH} 7.5-8.5,99^{\circ} \mathrm{C}$ & $\mathrm{H}_{2} \mathrm{O}, \mathrm{pH} 6-6.5,99^{\circ} \mathrm{C}$ & $\mathrm{NaCO}_{3}, 99^{\circ} \mathrm{C}$ \\
\hline Filtration and precipitation & Isopropanol & Isopropanol & Isopropanol \\
\hline Refined hydrocolloid & Drying/freeze-drying & Drying/freeze-drying & Drying/freeze-drying \\
\hline
\end{tabular}


Differences in the extraction procedures affect the sulfate and 3,6-anhydrogalactosyls content, which may change from 20 to $16 \%$ and 22 to $40 \%$, respectively, for carrageenan extracted from Hypnea musciformis (Rhein-Knudsen, Ale, Ajalloueian, Yu, \& Meyer, 2017). Analogously, the 3,6-anhydrogalactosyl content could be increased from 28 to $33 \%$ using $6 \% \mathrm{KOH}$ for alkali-modification during extraction (Moses, Anandhakumar, \& Shanmugam, 2015).

The traditional extraction techniques require chemical treatments, high temperatures, and long reaction times and may have effects on the hydrocolloid products, resulting in reduced functional properties, due to degradation of the polysaccharides during extraction and yield losses. Alternative extraction methods, such as enzyme-assisted extraction, microwave-assisted extraction, and ultrasound-assisted extraction have been proposed and have been extensively reviewed recently by Khalil et al. (2018).

Agar

Like carrageenan, agar is composed of a linear backbone chain of galactopyranosyl moieties, but whereas the 3,6-anhydrogalactopyranosyl is in the D-configuration in carrageenans, it is in the L-configuration in agar (Fig. 1). Araki (1958) was the first to solve the primary structure of agar and determined that it consists of two fractions: agarose, having a neutral unmodified backbone built up by D-galactosyl and 3,6-anhydroL-galactosyls, and a fraction which he termed agaropectin, which consists of D-galactosyls and L-galactosyls (Fig. 1). Modifications on agaropectin include sulfate, pyruvate and to a lesser extent various sugar molecules. Sulfation of C6 in the L-galactosyl residues is found in most agarophytes, but is particularly abundant in agar extracted from Porphyra species, hence the extracted agar from these species is referred to as porphyran. However, porphyran is considered the precursor of agar. Methylations on the 06 of Dgalactopyranosyls of porphyran have been detected. Whereas the percentage of sulfate is normally high in carrageenans, agar normally has less than 12 \% sulfate substitutions (Usov \& Zelinsky, 2013).

Like for carrageenans, the chemical composition of agar varies depending on extraction technique, i.e. water extraction or combined alkali modification and extraction (Table 1). The proposed mechanism for alkali modification of agar is not readily available in the literature, but is presumed to follow the same principles and essentially be similar to that proposed for carrageenan modification (Ciancia et al., 1993): ionization that results in electrostatic repulsion to destabilize the ${ }^{4} C_{1}$ chair conformation allowing anhydroring formation by nucleophilic displacement of the sulfate at position 6 . Reductive acid hydrolysis of agar extracted with water at $90{ }^{\circ} \mathrm{C}$ for $45 \mathrm{~min}$ from Gracilaria birdiae showed that this agar contained around 65 \% galactose, $25 \%$ 3,6-anhydrogalactose and $8 \%$ sulfate (Souza et al., 2012), but in another study, water extraction at $90{ }^{\circ} \mathrm{C}$ for $4 \mathrm{~h}$ gave agar derived from Gracilaria gracilis that contained $28 \%$ galactose, $35 \%$ 
160

161

162

163

164

165

166

167

168

169

170

171

172

173

174

175

176

177

178

179

180

181

anhydrogalactose and only $4 \%$ sulfate (Rodríguez, Matulewicz, Noseda, Ducatti, \& Leonardi, 2009). Water extraction (100 ${ }^{\circ} \mathrm{C}, 3 \mathrm{~h}$ ) of agar from Hydropuntia cornea gave a 3,6-anhydrogalactose and sulfate content of $35 \%$ and $6 \%$, respectively, while agar extracted from Hydropuntia dentata contained $18 \%$ anhydrogalactose and 8 \% sulfate (Pereira-Pacheco, Robledo, Rodríguez-Carvajal, \& Freile-Pelegrín, 2007; Rhein-Knudsen, Ale, Ajalloueian, Yu, et al., 2017). Applying alkali-modification of the porphyran blocks during extraction changed the composition of the Hydropuntia dentata agar to $35 \%$ anhydrogalactose and $5 \%$ sulfate (Rhein-Knudsen, Ale, Ajalloueian, Yu, et al., 2017).

Alginate

Alginate from seaweeds represents a family of negatively charged unbranched polysaccharides built via 1,4glycosidic linking of the two uronic acids, $\beta$-D-mannuronic (M) and $\alpha$-L-guluronic acid (G), which are C5 epimers. The mannuronic acid residues form $\beta-1,4$ linkages to give blocks of mannuronic acids in a linear conformation, whereas the $\alpha-1,4$ linkages formed by the guluronic acids provide a folded structure due to the introduction of a steric hindrance around the carboxyl groups (Fig. 3).

The uronic acids are arranged in segments of varying proportions of GG, MM, and MG-blocks (Fig. 3) that vary depending on the type, age, and life-stage of the macroalgae as a result of the way the alginate is synthesized in the algae (discussed below). The M/G ratios of alginates from different species of Sargassum have thus ben reported to vary from 0.2-1.2 and alginate from e.g. Sargassum fluitans from Cuba and Florida have been reported to have widely different M/G ratios of 0.52 and 1.18, respectively, (Torres et al., 2007). Padina sp. from Ghana has been shown to contain alginate having high M/G ratios of 1.5 (RheinKnudsen, Ale, Ajalloueian, \& Meyer, 2017), but alginate from Padina pavonica collected in Egypt has been reported to contain higher amounts of guluronic than mannuronic acid (Pereira, Gheda, \& Ribeiro-Claro, 2013).

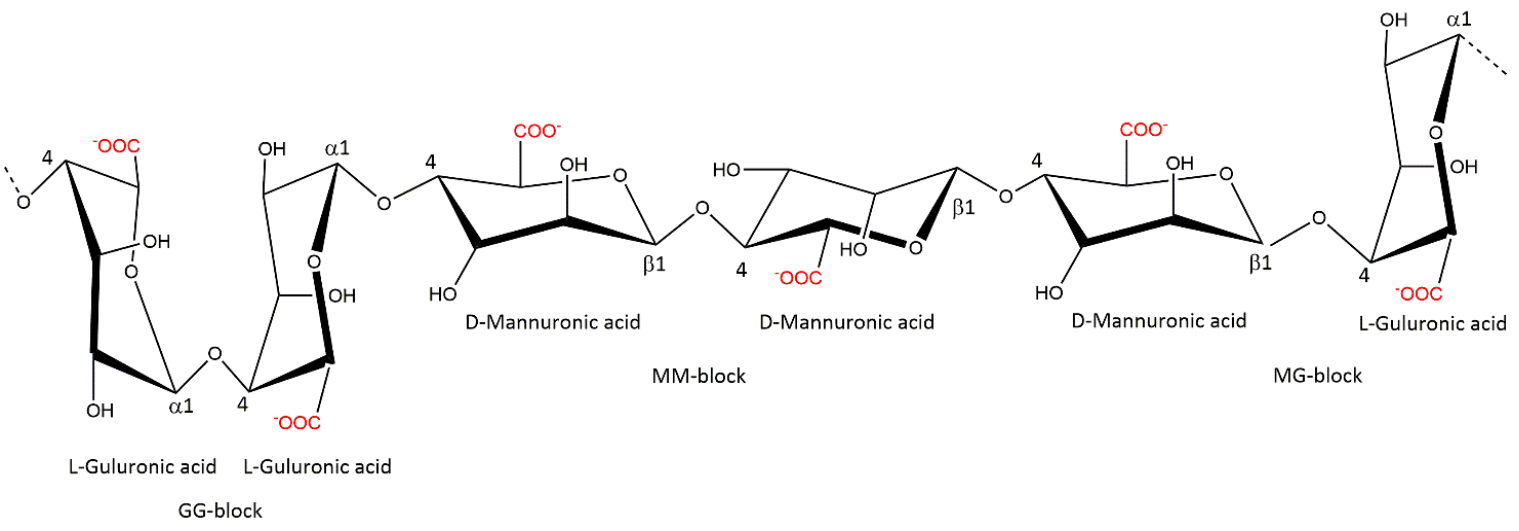

Fig. 3 Stylized chemical structure of alginate composed of $\alpha$-L-guluronic acid and $\beta$-D-mannuronic acid residues shown in stretches of GG-blocks, MM-blocks, and MG-blocks. 
Extraction protocols for alginate differ significantly from those of carrageenan and agar, Table 1, as the alginate is bound in the cell wall as insoluble alginate salts, i.e. calcium or magnesium alginate. Current extraction techniques therefore rely on conversion of these insoluble alginates to soluble ones. Normally, the counter ions are removed using acid to form insoluble alginic acid, and the alginates are subsequently extracted as sodium alginates. In addition, formaldehyde addition is used to remove phenolics (Table 1). The sodium alginate is separated from the seaweed residuals by filtration or centrifugation and then recovered by precipitation in alcohol (Calumpong, Maypa, \& Magbanua, 1999).

\section{Seaweed hydrocolloid biosynthesis}

Although the biosynthetic routes and detailed conversions involved in seaweed hydrocolloids synthesis are yet to be understood in detail, recent sequencing, gene annotation, and investigations of the enzymes involved in cell-wall polysaccharide synthesis in the red seaweed Chondrus crispus and the brown seaweed Ectocarpus siliculosus have cast important new light on the synthesis of hydrocolloid polysaccharides in red and brown macroalgae (Collén et al., 2013; Michel, Tonon, Scornet, Cock, \& Kloareg, 2010).

\section{Carrageenan biosynthesis}

It has been proposed that three classes of enzymes are involved in carrageenan biosynthesis: 1) galactosyl transferases ( $\alpha$ and $\beta$ ), catalyzing the polymerization of the galactose backbone; 2) sulfotransferases, adding sulfate substitutions to the newly synthesized galactose chains; 3) Gal-6-sulfurylases, sometimes referred to as sulfohydrolases, catalyzing the removal of sulfate at position 6 in the $\alpha$-galactopyranosyl monomer and subsequent formation of the 3,6-anhydro bridge (Fig. 4). The first two reactions, i.e. galactose polymerization and sulfate substitution, have been shown to occur in the Golgi apparatus, though none of the related enzymes have been characterized. Only a few steps of carrageenan biosynthesis, namely those involving the key galactose-sulfurylase reactions, have at this point in time been demonstrated experimentally with the isolation and characterization of the carrageenan specific enzymes (Genicot-Joncour et al., 2009; Lipinska, Collén, Krueger-Hadfield, Mora, \& Ficko-Blean, 2020). Sulfurylase activity, which is unique to red seaweeds, was first demonstrated by Wong \& Craigie (1978), who characterized an enzyme from the red seaweed $C$. crispus responsible for the conversion of $\mu$-carrageenan into k-carrageenan (Wong \& Craigie, 1978) (the first experimental data supporting the sulfurylase activity was already obtained by Rees et al. (1961), though with specific activity on porphyran, the precursor for agar (Rees, 1961)).

The presence of an enzyme catalyzing the conversion of v-carrageenan to t-carrageenan was then demonstrated in the red seaweed Calliblepharis jubata by Zinoun et al. (1997) (Zinoun, Diouris, Potin, 
Floch, \& Deslandes, 1997). Similarly, carrageenan sulfurylase activities have been demonstrated in Betaphycus gelatinus (Wang et al., 2014), Eucheuma striatum (Qin, Ma, Lou, \& Wang, 2015), and Gigartina stellata (Lawson \& Rees, 1970). Genicot-Joncour et al. (2009) purified two enzymes, sulfurylase I and sulfurylase II, from C. crispus that catalyze conversion of V-carrageenan to l-carrageenan (Genicot-Joncour et al., 2009). The enzymatic mechanism behind the conversion of galactopyranosyl 6-sulfate to 3,6anhydrogalactopyranosyl monomers is still unknown. However, this conversion is proposed to occur through a nucleophilic substitution in which the $C_{6}$ sulfate is removed and replaced by the hydroxyl group at position $3\left(\mathrm{C}_{3} \mathrm{OH}\right)$ on the sulfated $\alpha$-galactopyranosyl monomer, in a reaction similar to that which occurs during chemical modification of carrageenans using an alkali (Ciancia et al., 1993; Genicot-Joncour et al., 2009). The reaction by sulfurylases, i.e. the conversion of the sulfated galactopyranosyl monomers in the precursors, alters the hydrophobicity of the sugars and inverts the chair conformation from ${ }^{4} \mathrm{C}_{1}$ to ${ }^{1} \mathrm{C}_{4}$, which consequently gives the carrageenan the ability to form gels by helix formation (Fig. 4) (GenicotJoncour et al., 2009).

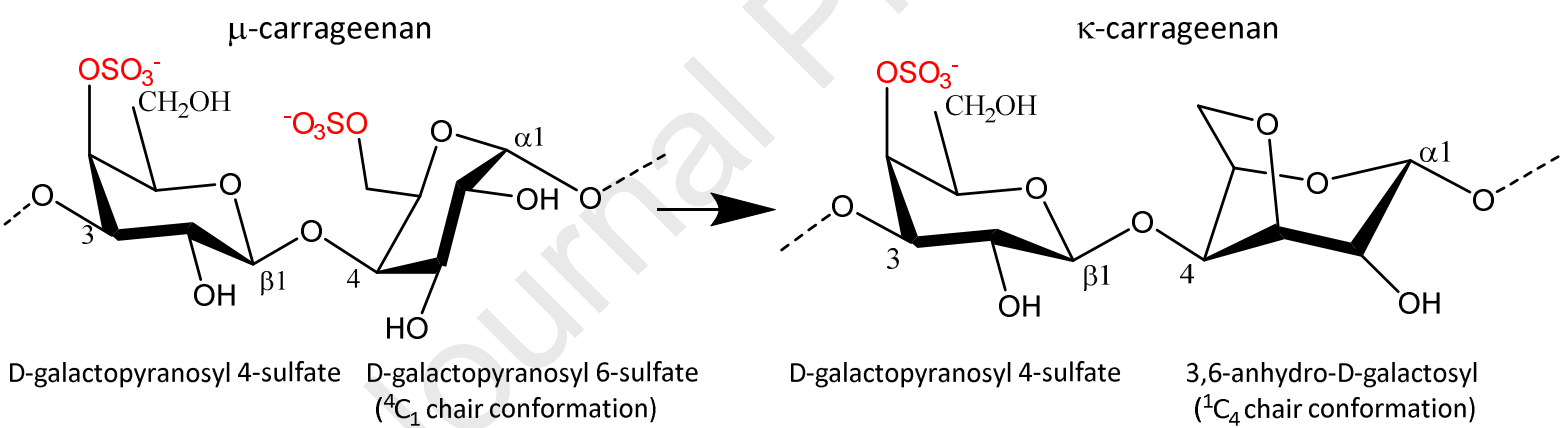

Fig. 4 Conversion of precursor $\mu$-carrageenan into k-carrageenan, a reaction catalyzed by sulfurylase enzymes.

\section{Agar biosynthesis}

234 The biosynthesis of agar in macroalgae is not understood in detail because the enzymes responsible for galactose polymerization and potential substitutions are yet to be characterized. Nevertheless, it is known that the proposed biosynthesis pathway begins with glycosylation of the alternating D- and L-galactose monomers in the Golgi apparatus, followed by potential sulfation by sulfotransferases, after which the polymers are transferred to the cell wall matrix for further modification of the precursor components by sulfurylases (Lee et al., 2017). of an anhydro-bridge (illustrated for K-carrageenan in Fig. 4), was demonstrated early by Rees et al. (1961) 
on porphyran, the biosynthetic precursor for agar, using an enzyme extract from the red seaweed Porphyra umbilicalis (Rees, 1961). Similar sulfurylase activity was more recently reported in Gracilaria dura (Shukla, Kumar, Prasad, Reddy, \& Jha, 2011). The conversion of galactopyranosyl 6-sulfate to 3,6anhydrogalactopyranosyl was verified in vivo in another porphyrin-containing red seaweed, Graciliaria chilensis (Hemmingson, Furneaux, \& Wong, 1996).

\section{Alginate biosynthesis}

Alginate is known to be synthesized in brown seaweeds via initial polymerization of D-mannuronic acid residues in the Golgi apparatus (Michel et al., 2010). Guluronic acid monomers are then generated in situ in the mannuronate polymers by mannuronan C5-epimerase (EC 5.1.3.37) catalyzed C-5 epimerization of Dmannuronic acid into L-guluronic acid (Nyvall et al., 2003). Algal C5-epimerase genes encoding AlgG-type epimerases (discussed further below), have recently been identified in several brown seaweeds, i.e. $L$. digitata, Saccharina japonica and E. siliculosus, and recent work by Fischl et al. (2016) and Inoue et al. (2016) has included successful heterologous expression of mannuronan C5-epimerases from E. siliculosus and S. japonica in E. coli and insect cells, respectively (Fischl et al., 2016; Inoue et al., 2016). Yet, detailed knowledge of alginate biosynthesis in brown macroalgae is still somewhat limited. In contrast, the alginate synthesis pathway, including the multiprotein complex involved and the function of mannuronan C5epimerases, is well characterized in alginate-producing bacteria, i.e. Azotobacter vinelandii and Pseudomonas spp., and has recently been eminently reviewed by Moradali, Ghods, \& Rehm (2018).

\section{Gel-formation}

\section{Carrageenans}

The exact mechanism of carrageenan gelation, i.e. the intermolecular interactions and ionic effects, is still a matter of debate. However, it is generally accepted that the gelation process involves a coil-helix transition and double helix formation followed by aggregation which is promoted by specific ions (Fig. 5). This gelation model is called the "domain model" and was originally proposed by Morris et al. (1980) (Morris, Rees, \& Robinson, 1980).

Carrageenans in solutions at high temperatures adopt random coil structures due to electrostatic repulsions between adjacent negatively charged chains. Upon cooling, the 3,6-anhydro-D-galactopyranosyl containing polymers change conformation to helix structures. Due to ${ }^{1} \mathrm{C}_{4}$ chair conformation, the $3,6-$ anhydro-galactopyranosyl units present in $\mathrm{k}$ - and l-carrageenan allow the carrageenan chains to form $\alpha$ helices. Occurrence of stretches without 3,6-anhydrogalactopyranosyl units, i.e. the precursors $\mu$ - and vcarrageenan having sulfated galactopyranosyl units in the ${ }^{4} C_{1}$ conformation, causes "kinks" in the chains, as 


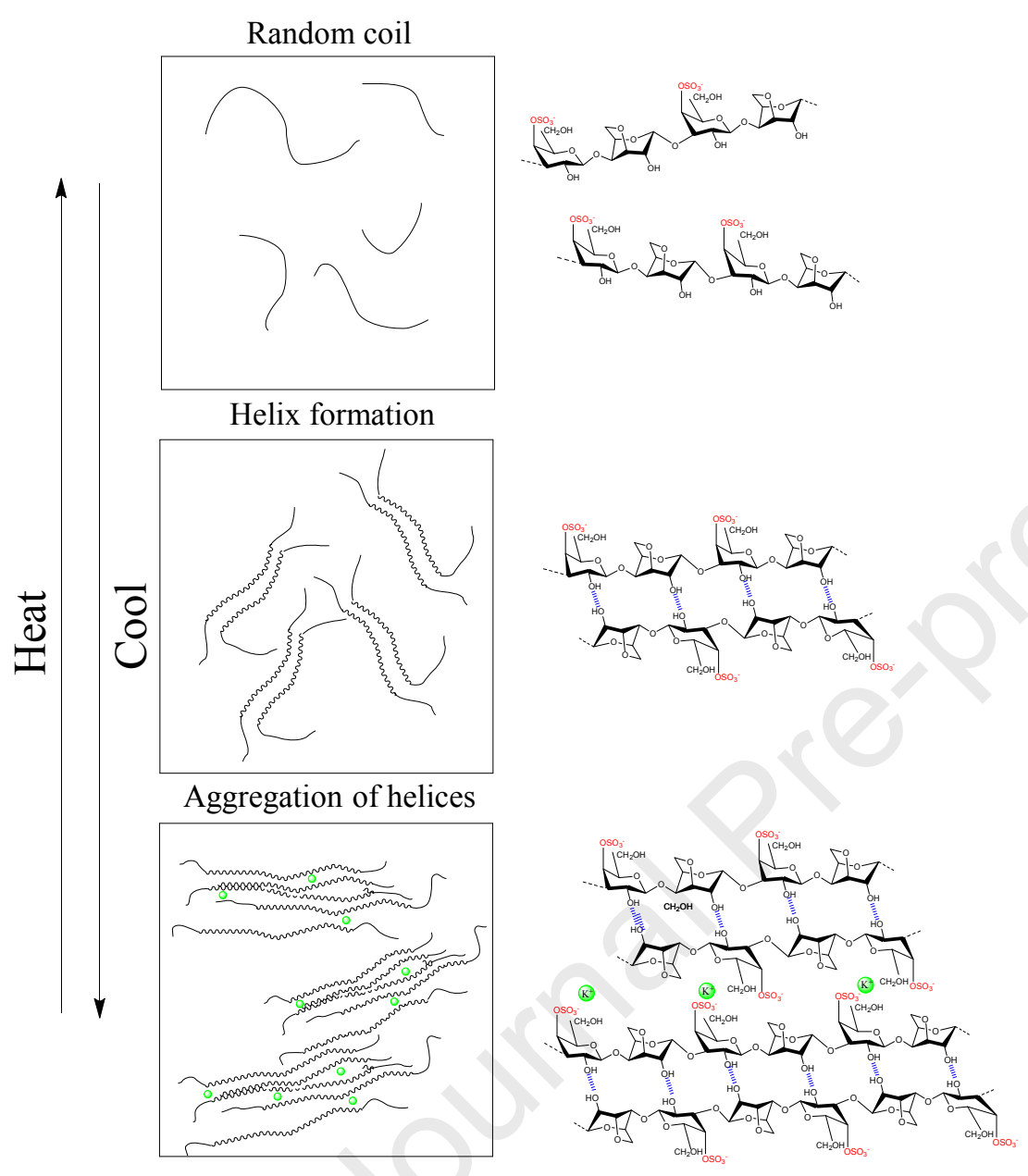

Fig. 5 The gelation mechanism for k-carrageenan in the presence of potassium ions.

Further cooling and presence of cations leads to aggregation of the helical carrageenan chains and consequently to the formation of a stable three dimensional network formed by the intermolecular interactions between adjacent carrageenan chains. The mechanisms which govern the conformational transitions are still highly debated and controversial. It is generally accepted that $\mathrm{k}$-carrageenans change conformation to a double-helical structure prior to gelation (Yuguchi, Thu Thuy, Urakawa, \& Kajiwara, 2002). Helix formation, and the adherent gelation, probably occur because of intra- and intermolecular interaction associations, i.e. hydrogen bonds and van der Waals forces of attraction, between hydroxyl groups and potentially also the hemiacetal oxygen, as observed for other gelling polysaccharides, e.g. starch (Tako, Tamaki, Teruya, \& Takeda, 2014). In an attempt to resolve the conformational transition for lcarrageenan, Schefer et al. (2014) performed atomic force microscopy (AFM) imaging of t-carrageenan. 
Their results strongly support the conclusion that t-carrageenan in salt solution consists of an intramolecular single-stranded helix and not a double-stranded one as previously claimed. However, possible intermolecular dimeric double helix formation upon increasing polymer concentration cannot be excluded, and a double helix has been proposed by earlier studies supported by X-ray differentiation and differential scanning calorimetry (Schefer, Adamcik, \& Mezzenga, 2014).

The binding of ions plays an important role in the aggregation process because binding of ions decreases the effective charge density of the hydrocolloids and hence eases aggregation by decreasing electrostatic repulsion. Different molecular interactions between the carrageenan chains and the ions have been proposed. For example, Tako et al. (2014) described that large univalent cations such as $\mathrm{K}^{+}$participate in both intramolecular and intermolecular associations that occur via a combination of cation bridges between the cation and the sulfate on the galactopyranosyl 4-sulfate moieties and electrostatic forces between the cation and the ether-bound oxygen on the adjacent 3,6-anhydrogalactopyranosyl moieties (Tako et al., 2014), whereas others have speculated that the ions interact with two sulfate groups on opposing chains through ionic bonds (Tecante \& Núñez, 2012). Nevertheless, due to the charge of the carrageenan chains, it is not surprising that the electrostatic repulsion is shielded by the ions and it can thus be assumed that the charged ions function to stabilize the junction zones between the helices without hindering aggregation.

The effects of different cations on carrageenan gelation have been extensively studied. Monovalent cations that induce $\mathrm{k}$-carrageenan gelation include $\mathrm{K}^{+}, \mathrm{Rb}^{+}, \mathrm{Cs}^{+}$and high amounts of $\mathrm{Na}^{+}$and $\mathrm{Li}^{+}$. Divalent cations such as $\mathrm{Ca}^{2+}, \mathrm{Ba}^{2+}$ and $\mathrm{Mg}^{2+}$ likewise have the ability to induce gel formation. Divalent cations have been shown to increase the gel strength of $\mathrm{k}$-carrageenan better than monovalent cations, with the exception of potassium that probably binds specifically to the $\mathrm{K}$-carrageenans because $\mathrm{K}^{+}$are more effective at shielding the electrostatic repulsion (Thrimawithana, Young, Dunstan, \& Alany, 2010). Likewise, cation-specific effects are observed for t-carrageenan aggregation where the divalent ion $\mathrm{Ca}^{2+}$ shows a very strong helixstabilizing effect. Calcium analogously cross-links the two t-carrageenan helices, presumably by salt bridges. However, the charged sulfate esters on the other side of the monomer encourage an extended conformation via a repulsion effect of the negative sulfate groups and thus inhibit gelation while promoting viscosity in the solution (Wu \& Imai, 2012). Ion-specificity seems to be related to the specific type of carrageenan and the possible interaction between these two components. It is suggested that the radius of the cation seems to be most important for potential interaction with k-carrageenan, which forms the strongest gels with potassium, whereas the valence of the cations seems to have a higher effect for cationdependent I-carrageenan gelation (Rinaudo, Karimian, \& Milas, 1979). Improvements in analytical 
techniques over the years have resulted in many discoveries related to hydrocolloid gelation, but much remains to be determined in order to obtain a greater understanding of the molecular events of this process. Improved insight into the molecular details would ideally lead to a greater understanding of polymer conformation transition, and such knowledge could potentially be used for designing carrageenans with specific properties, for example by controlling polymer-cation ratio.

Agar

The physico-chemical properties of agar are outstanding amongst the seaweed hydrocolloids. The chemical structure of agar (i.e. specifically of agarose, which is purified agar devoid of agaropectin), basically consists of D-galactopyranosyl residues and 3,6-anhydro-L-galactopyranosyl monomers bound together by alternating $\alpha-1,3$ and $\beta-1,4$ linkages (Fig. 1). This structural configuration allows the polysaccharide to form helices comparable with carrageenans (Usov \& Zelinsky, 2013). It is alluring to assume that agar gelation likewise occurs through the aggregation of these helices, though without the help from ions. Tako and Nakamura (1988) have proposed a mechanism for $\alpha$-helix formation of agar during gel formation in which the helix is stabilized by hydrogen bonds between the ether-bond and the $\mathrm{C}_{2} \mathrm{OH}$ in the anhydro-Lgalactopyranosyl residues opposite one another. As for the carrageenans, the presence of its biological precursor porphyran, inhibits gel formation due to the lack of anhydrogalactopyranosyl residues. The aggregation of the agar helices (agarose chains) is more favorable than for carrageenans and relies entirely on intermolecular and intramolecular hydrogen bonding in a structural network which has been compared to a tetrahedral ice-like structure (Tako et al., 2014), giving agar the highest gel strength of the red seaweed hydrocolloids in pure water (Tako \& Nakamura, 1988).

Alginate

Alginate gelation is normally described by the "egg-box" model originally proposed by Grant et al. in 1973. In the presence of divalent ions, mostly $\mathrm{Ca}^{2+}$, the ions can bind to the carboxyl groups in alginate and act as cross-linkers that stabilize the alginate chains by formation of a gel network (Fig. 6). The gel network is described as the "egg-box" because gelation predominantly involves GG-blocks into which the ions fit like eggs in a box (Grant, Morris, Rees, Smith, \& Thom, 1973). Alginate gels can also be prepared with other ions and the affinity of alginate towards divalent ions decreases in the following order: $\mathrm{Pb}>\mathrm{Cu}>\mathrm{Cd}>\mathrm{Ba}>$ $\mathrm{Sr}>\mathrm{Ca}>\mathrm{Co}, \mathrm{Ni}, \mathrm{Zn}>\mathrm{Mn}$ (depending on charge and ionic radius); however, calcium is normally used for inducing alginate gelation (Mørch, Donati, Strand, \& Skjåk-Bræk, 2006). 


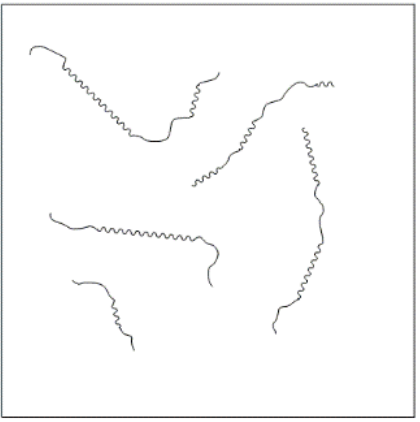

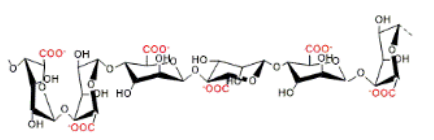

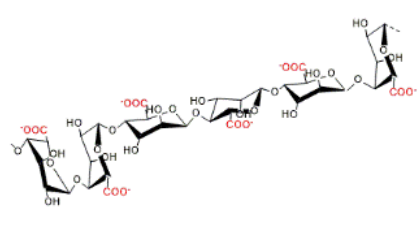

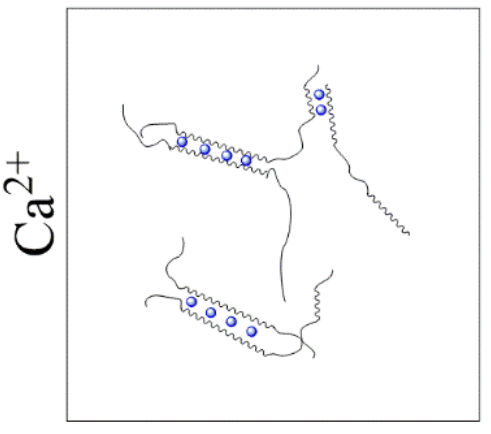

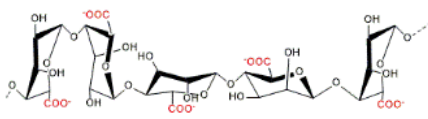
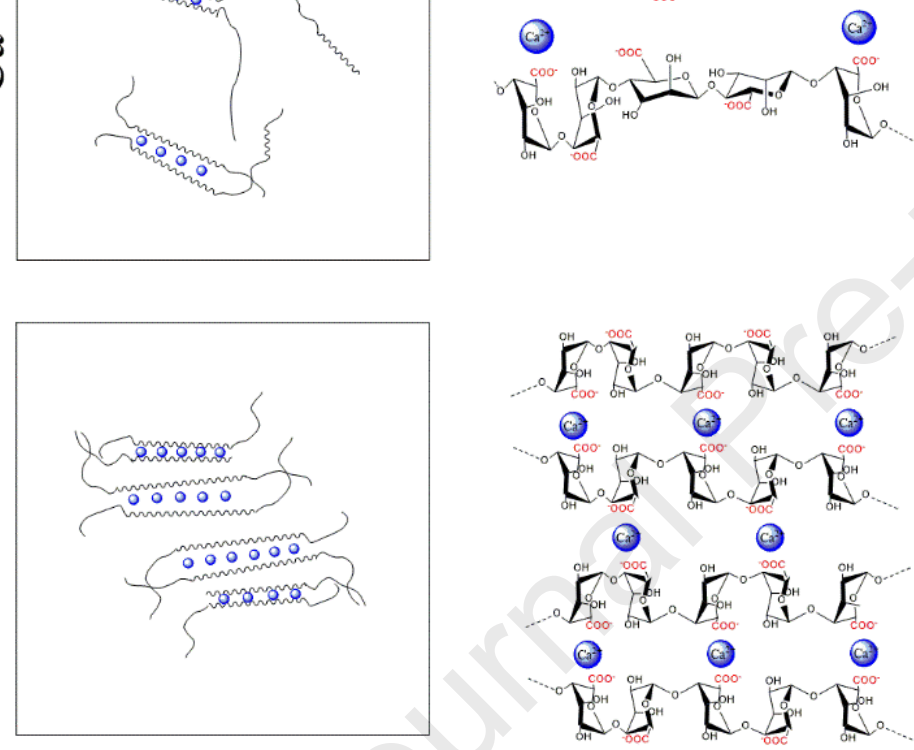

Fig. 6 The gelation mechanism for alginate in the presence of calcium ions.

The calcium ions preferentially bind to the GG-blocks, as the structure of the GG-blocks allows a high degree of coordination of the divalent ions. Binding of ions thus results in tightly held junctions between aligned GG-blocks. The MG-blocks also participate in gel formation although these blocks form weaker junctions and thus weaker gels. The relative amount of guluronate residues, more precisely the amount of polyguluronic acid blocks (GG-blocks), and hence the M/G ratio thus has a profound impact on the gelation properties of alginate: alginates with low $M / G$ ratio generally produce firm and brittle gels, whereas alginates with high $\mathrm{M} / \mathrm{G}$ ratios form more elastic gels (Mørch et al., 2006).

Minor changes at the molecular level have a huge impact on the gelling properties of the seaweed hydrocolloids, i.e. carrageenans with the same amount of precursor units may show different rheological 
properties as a result of precursor distribution. In addition, molecular weight, lengths of chains, and ionic contents and strengths all have significant effects on the gelation abilities of these carbohydrates.

\section{Carrageenans}

Mtolera and Buriyo (2004) tested the seasonal variations of alkali modified carrageenans extracted from Tanzanian Hypnea musciformis and showed that gel strengths at $1 \% \mathrm{w} / \mathrm{v}$ in $0.1 \mathrm{M} \mathrm{KCl}$ estimated at $25{ }^{\circ} \mathrm{C}$ ranged from $77-198 \mathrm{~g} / \mathrm{cm}^{2}$. Similar differences were observed in gelling and melting temperatures which ranged from $50-59{ }^{\circ} \mathrm{C}$ and $67-70{ }^{\circ} \mathrm{C}$, respectively (Mtolera \& Buriyo, 2004). These authors did not correlate the gelation properties with the composition of the carrageenans extracted in different seasons, but this has been done with carrageenans extracted from Hypnea musciformis in Ghana. Here, gelation properties were estimated using $1.5 \%$ carrageenan with $1 \% \mathrm{KCl}$, and gelling and melting temperatures were found to be $\sim 36^{\circ} \mathrm{C}$ and $60{ }^{\circ} \mathrm{C}$, respectively. Gelling and melting temperatures were shown to increase with increasing amounts of 3,6-anhydrogalactose (Rhein-Knudsen, Ale, Ajalloueian, Yu, et al., 2017). Similar results have been obtained for K-carrageenan extracted from the commercially used Kappaphycus alvarezii and it was also shown that gel strength increases with increasing $\mathrm{KCl}$ concentration (Manuhara, Praseptiangga, \& Riyanto, 2016). Rheological analyses of $\mathrm{k}$ - and $\mathrm{l}$-carrageenan gels with different ions have demonstrated that increasing counter ion concentration above a certain threshold has a negative effect on gel formation; this phenomenon is interpreted as indicative of a maximum packing or cross-linking density of the carrageenans (Thrimawithana et al., 2010).

\section{Agar}

Gelling and melting temperatures have been determined for agar extracted from Gracilaria vermiculophylla both by using water and by combined extraction and modification: Native agar exhibits gelling and melting temperatures at $22{ }^{\circ} \mathrm{C}$ and $60{ }^{\circ} \mathrm{C}$, whereas modified agar gelled and melted at $37{ }^{\circ} \mathrm{C}$ and $98{ }^{\circ} \mathrm{C}$, respectively (Arvizu-Higuera, Rodríguez-Montesinos, Murillo-Álvarez, Muñoz-Ochoa, \& Hernández-Carmona, 2008). Similar differences were observed for gel strengths estimated at $22{ }^{\circ} \mathrm{C}$, namely $72 \mathrm{~g} / \mathrm{cm}^{2}$ for the native agar and $1064 \mathrm{~g} / \mathrm{cm}^{2}$ for the alkali-modified agar owing to the differences in 3,6-anhydrogalactose contents (Arvizu-Higuera, Rodríguez-Montesinos, Murillo-Álvarez, Muñoz-Ochoa, \& Hernández-Carmona, 2008). Along with the differences in 3,6-anhydrogalactose contents, the differences in macroscopic properties are due to differences in amounts of methyl substitutions and molecular weights. As for all the seaweed hydrocolloids, the higher the molecular weight, the greater the probability of forming a stable gel network through molecular interactions. A comparison of agar samples having varying amounts of methyl substitutions has shown that amount and position of methylations affect the gelation mechanism and 
allows it to occur at different temperatures (Praiboon, Chirapart, Akakabe, Bhumibhamon, \& Kajiwara, 2006).

Alginate

The gelation properties of alginate are normally accessed by a methodology that relies on gel formation using $\mathrm{CaCO}_{3}$ and D-glucono- $\delta$-lactone to ensure a gradual calcium release (Draget, $\varnothing$ stgaard, \& Smidsrød, 1991). Using oscillatory rheology, Fernández Farrés and Norton (2014) made a comparison of the gelling profiles of two different alginates of different molecular size but with equivalent fractions of guluronic acids. The study showed that high molecular weight alginate fluid gels exhibited faster formation kinetics, enhanced viscosities, greater $\mathrm{G}^{\prime}$ and more solid-like behavior than those produced with low molecular weight alginates (Fernández Farrés \& Norton, 2014). Funami et al. (2009) made similar experiments on alginate samples of comparable molecular weights and different mannuronic and guluronic acid ratios, and observed that at low calcium concentrations mannuronic rich alginate produced higher $\mathrm{G}^{\prime}$ values than guluronic acid rich alginates, whereas this result was inverted at high calcium concentrations. Hence, alginate gelation is not only dependent on calcium dose but also on the composition and sequence pattern of the alginate. In their study, the mannuronic rich alginate with an $M / G$ ratio of 0.79 showed a $G^{\prime}$ value of 134.5 $\mathrm{Pa}$ at $\mathrm{CaCO}_{3}$ dose of $3.75 \mathrm{mM}$, whereas the guluronic rich alginate with an $\mathrm{M} / \mathrm{G}$ ratio of $0.41 \mathrm{had}$ a $\mathrm{G}^{\prime}$ of $30.6 \mathrm{~Pa}$ - increasing the calcium dose to $15 \mathrm{mM}$ gave $\mathrm{G}^{\prime}$ values of $782.1 \mathrm{~Pa}$ and $1997.6 \mathrm{~Pa}$, respectively (Funami et al., 2009). The data were obtained using $0.5 \mathrm{w} / \mathrm{v} \%$ alginate and $15 \mathrm{mM}$ D-glucono- $\delta$-lactone at $20{ }^{\circ} \mathrm{C}$ for $6 \mathrm{~h}$ with an applied strain of $1 \mathrm{~Hz}$ (Funami et al., 2009). In another study, using $1.5 \mathrm{w} / \mathrm{v} \%$ alginate, $15 \mathrm{mM}$ D-glucono- $\delta$-lactone and $22.5 \mathrm{mM} \mathrm{CaCO}_{3}$, alginates extracted from different Sargassum samples and having $M / G$ ratios of 0.47 and 0.70 showed $\mathrm{G}^{\prime}$ values of $1.1 \mathrm{~Pa}$ and $35.4 \mathrm{~Pa}$, respectively. In the same study, alginate with an M/G ratio of 1.85 from Padina antillarum gave a G' value of $376.3 \mathrm{~Pa}$ at the same reaction conditions. Due to the higher M/G ratio, it was assumed that this $P$. antillarum alginate would produce gels of lower strength than those with M/G ratios of 0.47 and 0.70 from Sargassum (RheinKnudsen, Ale, Ajalloueian, \& Meyer, 2017). Many Sargassum alginates have M/G ratios around or below one and high contents of GG-blocks but several studies report poor gelling properties of the Sargassum alginates (Mchugh, 2003).

\section{Interactions with other components in food matrices}

\section{Interactions with proteins}

In the food industry, carrageenans are used extensively in dairy products to adjust viscosity and in addition to the gelation mechanisms outlined above, the carrageenans also work by interaction with casein micelles. 
The negatively charged carrageenans are believed to interact directly with k-casein located at the surface of casein micelles. Both $\mathrm{k}$ - and l-carrageenans interact in this way with casein micelles, but the complexes differ in texture and microstructure (Arltoft, Ipsen, Madsen, $\&$ de Vries, 2007). Alginate is also widely used to reduce fat in different types of restructured meat products because of its emulsion-stabilizing and thickening properties. In model systems with bovine serum albumin, the intermolecular interactions between alginates and proteins have been shown to result in formation of an alginate:bovine serum albumin complex. The complex formation is a result of electrostatic forces between the positively charged stretches in the protein and the negatively charged carboxylic groups of the alginate (Zhao, Li, Carvajal, \& Harris, 2009). In complex meat systems, alginate also interacts with proteins. Recently, addition of alginate to frankfurters to partially substitute $25-50 \%$ of pork fat and thus decrease overall fat content, was shown to retain cooking yield, hardness, and sensory perception of juiciness (Kang, Wang, Li, Li, \& Ma, 2020). Yet, the more detailed assessment of the molecular interactions between the alginate and meat proteins in the frankfurter matrix showed that alginate induced secondary and tertiary structural changes in the meat proteins; the changes included increases in $\beta$-sheet, $\beta$-turn and random coil structures and were interpreted as being due to hydrophobic interactions and hydrogen-bond formation between the alginate and certain amino acids in the proteins such as tyrosine and tryptophane residues (Kang et al., 2020).

\section{Interactions with aroma compounds and effect on flavour release}

Although the main effect and intent of hydrocolloid addition to foods is to modify viscosity and gelation, it is known that the addition may also affect - usually decrease - the perceived flavor (Paravisini and Guichard, 2017). In addition to sensory assessment, direct effects of hydrocolloids additives on aroma compounds and flavour release is objectively measured as a mass transfer or phase partitioning coefficient; this coefficient is expressed as the ratio between the flavor compound concentration in the air phase above the product versus the corresponding flavour concentration in the product at equilibrium (Bylaite, Ilgunaite, Meyer, \& Adler-Nissen, 2004). In aqueous systems, addition of L-carrageenan appears to have a very limited effect on flavour release (Chana, Tromelin, Andriot, \& Guichard, 2006). In contrast, a study involving systematic series of volatile, aromatic compounds in $\lambda$-carrageenan model solutions has shown that $\lambda$-carrageenan slightly suppresses release rates and partitioning coefficients of the most volatile aroma compounds - however, neither viscosity or carrageenan concentration (from 0.1-0.5\%) affect the aroma compound partitioning or release rates (Bylaite et al., 2004). The latter result indicates that even if $\lambda$ carrageenan addition profoundly increased the macroscopic viscosity, the water mobility and air-water partitioning of volatile aroma compounds essentially remain unchanged. 


\section{4 \\ Enzymatic and microbial carrageenan-modification}

\section{$455 \quad$ Carrageenases}

456

Carrageenases are glycoside hydrolases that cleave the $\beta-1,4$ linkages in the carrageenan backbone to produce carrageenan-oligos. These enzymes are named according to their substrate specificity, i.e. $\mathrm{k}$ carrageenases (EC 3.2.1.83), L-carrageenases (EC 3.2.1.157), and $\lambda$-carrageenases (EC 3.2.1.162). Based on their amino acid sequences they belong to distinct glycoside hydrolase (GH) families, specifically GH16 ( $\mathrm{K}-$ carrageenases), GH82 (mainly t-carrageenases), GH150 ( $\lambda$-carrageenases), and exo-acting carrageenases classified into GH2, GH127, GH129 (Hettle et al., 2019), and in the recently created family GH167. The GH167 family has in fact been generated based on the recent discovery of $\mathrm{K} / \mathrm{L}$-carrageenan specific enzymes encoded by a carrageenan-specific polysaccharide utilization locus in four Pseudoalteromonas species isolated from red seaweeds (Hettle et al., 2019; Lombard, Golaconda Ramulu, Drula, Coutinho, \& Henrissat, 2014).

When it comes to the seaweeds, no carrageenases have been predicted from genome sequence analysis of the carrageenan-containing red seaweed C. crispus (Collén et al., 2013). However, the key enzymatic conversion steps in the pathway for carrageenan biosynthesis have recently been outlined for $C$. crispus (red macroalga) (Lipinska et al., 2020). The enzyme battery involved in the carrageenan biosynthesis includes several galactose-sulfurylases, carbohydrate-sulfotransferases, glycosyltransferases, and C. crispus moreover harbors three genes that appear to encode GH16 hydrolases. However, the GH16 enzymes from C. crispus categorize in the same clade as bacterial agarases, porphyranases, and some other enzymes from the red algae Porphyra umbilicalis; nevertheless, the GH16 hydrolases encoded by C. crispus are suggested involved in remodeling of carrageenan since agar and porphyrin are not present in C. crispus (Lipinska et al., 2020).

According to the CAZY.org-database currently known carrageenases thus mainly come from marine bacteria such as Flavobacteriaceae, Bacteroidites, and $\gamma$ Proteobacteria. Explorative screening studies indicate that enzymatic carrageenan hydrolytic activity is widespread in marine bacteria, notably in Bacteroidites and Proteobacteria, isolated from red algae (Kalitnik, Nedashkovskaya, Stenkova, Yermak, \& Kukhlevskiy, 2018).

Recently, the genome of the marine bacterium Colwellia echini $\mathrm{A}^{\top}{ }^{\top}$ (isolated from the intestine of a sea urchin collected in Øresund, Denmark) was shown to harbor two gene clusters (polysaccharide utilization loci), for degradation of agar and carrageenan, respectively (Christiansen et al., 2020). Notably, the 
carrageenolytic gene cluster was reported to encode all the enzymes required for complete degradation of $\mathrm{K}$-carrageenan and t-carrageenan as well as furcelleran (Christiansen et al., 2020). Furcelleran is a mixed type of high gelling k-carrageenan, also used to form gels in pharma and food applications (E number E407). Despite these recent important findings, the GH82 l-carrageenases from Alteromonas fortis, Cellulophaga sp., Microbulbifer thermotolerans, and Zobellia galactanivorans DsijT remain the most studied, especially with regard to their potential for generating carrageenan derived oligomers. Various strains of the marine bacterium Wenyingzhuangia, including $W$. fucanolytica and $W$. aestuarii (OF219) are also listed in the CAZY.org-database as encoding endo-acting GH16 k-carrageenases. For example, a k-carrageenase from $W$. aestuarii (OF219) has recently been cloned and reported suitable for production of $\mathrm{k}$-carrageenan oligomers (Shen, Chang, Chen, \& Dong, 2018). The production of oligo-carrageenans by enzymes offers advantages over production by acid hydrolysis because of the specificity provided by the enzymes. As mentioned above, there has been controversy over the safety of carrageenans in the past and according to David et al. (2018) mainly three issues still remain partly unsettled: i) there are only limited data on daily intake of carrageenans and a recommended (acceptable) daily dietary intake has not been specified; ii) the translation of data from animal studies to humans has been problematic because carragenan levels applied in animal models have usually exceeded those used in food products; iii) Recent human studies are based on interventions on only few persons producing only marginal (or no) changes between groups or between onset and final values, making the conclusions uncertain: For example, one human study with 12 ulcerative colitis patients showed that three of the patients who received carrageenan in capsules relapsed, whereas none of the patients who received placebo-containing capsules relapsed (Battacharyya et al., 2017); in another recent study involving 13 prediabetic persons, 8 of the participants followed a carrageenan free diet for 12 weeks, and the remaining 5 participants followed a comparable carrageenan containing diet (carrageenan intake of ca. $250 \mathrm{mg} /$ day). The results indicated that a carrageenan-free diet gave improved glucose tolerance, but did not identify changes in the participants on the carrageenan-containing diet (Feferman, Bharracharyya, Oates, Haggerty, Wang, Varady, \& Tobacman, 2020). Although more research on the digestive fate of carrageenans and oligo-carrageenans is indeed warranted, carrageenans are currently fully approved and widely used as food additives. In 2015 the World Health Organization expert committee on Food Additives (JECFA) furthermore reinstated that use of up to $1 \mathrm{~g} / \mathrm{L}$ of carrageenan even in infant 512 formula is safe and not of concern (David et al., 2018).

513 To understand the molecular basis of carrageenan degradation, Barbeyron et al. (1994) characterized a kcarrageenase, the CgkA from the marine bacterium Pseudoalteromonas carrageenovora from which several hydrolases involved in the degradation of carrageenan have been purified. The results obtained represent the first sequence determination of a carrageenase. Their deduced protein sequence presented significant 
sequence similarities with various $\beta-1,3-1,4$-glucanases and CgkA was therefore designated as a new member of the GH16 family (Barbeyron, Henrissat, \& Kloareg, 1994). The k-carrageenase was shown to be endo-hydrolase operating with a molecular mechanism retaining the anomeric configuration when it produces oligo-carrageenans with a degree of polymerization (DP) of 2 and 4 (Potin et al., 1995). A recent report on cloning and characterization of a $\mathrm{k}$-carrageenase from another $P$. carrageenovora strain $(P$. carrageenovora ASY5) confirms that the main DP2 and DP4 hydrolysis products of this $\mathrm{k}$-carrageenase action consist of repeating units of $\beta$-D-galactopyranose-4-O-sulfate and 3,6-anhydrogalactopyranose moieties (Xiao, Zeng, Li, Zhu, Xiao, \& Ni, 2018).

The first crystal structure of a carrageenase was deduced by Michel et al. (2001) who showed that the CgkA from $P$. carrageenovora folds into a curved $\beta$-sandwich formed by two closely packed and anti-parallel $\beta$ sheets creating a tunnel-shaped active site, which further suggests a processive mode of action. The kcarrageenan chain is composed of alternating neutral and negatively charged sugars. To accommodate the dual nature of its substrate, CgkA in its active site features both conserved aromatic and basic residues which are predicted to interact with the 3,6-anhydrogalactosyls and galactosyl-4-sulfate moieties, respectively (Michel, Chantalat, Duee, et al., 2001). The same structural features have been observed for the ZgCgkA k-carrageenase from Z. galactanivorans, which was shown to have additional elements such as a CBM and a distinct tunnel topology that resulted in an opposite direction of processivity (Matard-Mann et al., 2017).

Barbeyron et al. (2000) also characterized the first t-carrageenases from Z. galactanovorans and Alteromonas fortis and showed that l-carrageenases, like k-carrageenases, have an endolytic mode of action but unlike $\mathrm{K}$-carrageenases, these l-carrageenases were shown to be inverting hydrolases. The two Lcarrageenases both release oligo-carrageenans DP2 and DP4 as their end-product (Barbeyron, Michel, Potin, Henrissat, \& Kloareg, 2000). The three-dimensional structures of the t-carrageenase (CgiA_Af) from A. fortis was later resolved, and it was revealed that the enzyme folds into a right-handed parallel $\beta$-helix flanked by two domains, $A$ and $B$, where $A$ upon binding to substrate shifts toward the $\beta$-helix groove to form a tunnel consistent also with the processive behavior of I-carrageenases. I-Carrageenan, which consists of only negatively charged sugars, is recognized by CgiA essentially through ionic interactions 545 Fanchon, et al., 2001).

$546 \lambda$-carrageenase activity has also been identified from the marine bacterium $P$. carrageeronovora. Guibet et 547 al. (2007) cloned and characterized the first $\lambda$-carrageenase producing oligo-carrageenans DP2 to DP8. 
family of GHs which is unrelated to families $\mathrm{GH} 16$ and GH82 that contain the k- and t-carrageenases, respectively. CglA was demonstrated to proceed according to an endolytic mode of action and a mechanism of inversion of the anomeric configuration. Although the catalytic domain structure of $\lambda$ carrageenase remains to be resolved it is likely that this enzyme has a modular architecture with at least two domains connected by a linker, including a $\beta$-propeller domain at the $N$-terminus (Guibet et al., 2007). Apart from representing important scientific insight, this knowledge has important implications for understanding how microbial enzymes may be employed to modify carrageenans for tailor-made physical functionalities.

\section{Sulfatases}

The carrageenans are heavily sulfated and, as explained above, these negatively charged ions have effects on the gelation properties of the individual polysaccharides. Re-arrangement or removal of sulfates offers another alternative for modulating the gelation properties of the hydrocolloids. It also offers the potential for production of neutral mono- and oligosaccharides which can be used for energy production for example.

Sulfatases are the enzymes responsible for the removal of sulfates. Compared to the relatively high number of described carrageenases, only a few carrageenan sulfatases have been characterized and, as with the carrageenases, these are all of marine bacterial origin. Sulfates are grouped into three classes based on sequence homology, structure, and mechanism where Type I sulfatases, also known as formylglycinedependent sulfatases, represent the majority of known sulfatases. These sulfatases require a posttranslational conversion of cysteine or serine into a formylglycine amino acid residue that is essential for catalysis, and this conversion is performed by a formylglycine generating enzyme. Other sulfatases include Type II, Fe(II) $\alpha$-ketoglutarate-dependent alkylsulfatases and Type III, the $\mathrm{Zn}^{2+}$ or $\mathrm{Mn}^{2+}$-dependent metallo$\beta$-lactamases (Barbeyron et al., 2016).

All characterized carrageenan sulfatases with one exception have been identified as being formylglycinedependent sulfatases. The formylglycine-dependent sulfatases adopt a similar fold comprising two $(\alpha / \beta)$ domains, a large N-terminal domain containing the catalytic pocket, and a smaller C-terminal domain. The active site encompasses the catalytic nucleophile formylglycine and nine additional conserved residues, four acidic/polar residues coordinating a calcium ion which binds and activates the sulfate group of the substrate, and five basic amino acids stabilizing the formylglycine and/or binding the sulfate group (Barbeyron et al., 2016). Two mechanisms for sulfate removal by formyl-glycine dependent sulfatases have been proposed, which differ in the hydration state of the formylglycine. However, both propositions agree that the last step of the reaction involves covalent binding of the formylglycine modified amino acid and 
sulfate followed by regeneration of formylglycine by hydrolysis, which results in an overall reaction in which the retention of the carbon is retained (Williams, Denehy, \& Krenske, 2014).

The first sulfatase targeting seaweed hydrocolloids was carrageenan sulfatase which was discovered by Weighl and Yaphe (1966) from a protein extract from the marine bacterium P. carrageenovora (Weigl \& Yaphe, 1966). This carrageenan sulfatase, called 4-O-k-carrabiose sulfatase, was shown to have an exo-type mode of action that removes the sulfate ester at the non-reducing end of oligo-k-carrageenans (McLean \& Williamson, 1979). Recently, Préchoux et al. (2013) recombinantly expressed a 4S-iota carrageenan sulfatase purified from Pseudoalteromonas atlantica T6c which converts l-carrabiose into $\alpha$-carrabiose repeating units by removing the sulfate ester at position 4 of the D-galactosyl residues through an endo mode of action. Sequence alignments confirmed that this sulfatase belongs to the Type I formylglycinedependent sulfatases, characterized by a cysteine included in a signature sequence of 12 amino acids. Cloning experiments resulted in enzymes having lower activity than the native protein, which suggests that only a small fraction of the cysteine or only a low fraction of the overexpressed protein had been maturated in the overexpressed protein. Co-expression of a formylglycine-generating enzyme may be used to address these issues. $\mathrm{k}$-carrageenan, which is also composed of galactose-4-sulfate, was not desulfated by this sulfatase, suggesting that the residue adjacent to galactose- 4-sulfate is important for desulfation (Préchoux, Genicot, Rogniaux, \& Helbert, 2013). Similarly, a formylglycine-dependent endo-4-O-Kcarrageenan sulfatase identified from $P$. atlantica T6c yielded $\beta$-carrabiose repetition moieties (Préchoux, Genicot, Rogniaux, \& Helbert, 2016).

Genicot et al. (2014) identified another l-carrageenan sulfatase that also catalyzes the removal of the 40 sulfate. However, despite the finding that this enzyme has the same specificity as the t-carrageenan sulfatase from $P$. atlantica, sequence analysis showed no sequence homology between this enzyme and the $P$. atlantica sulfatase nor with other known sulfatases, which indicates that this sulfatase could be the first characterized member of a new sulfatase family (Genicot, Rogniaux, Meslet-Cladière, Barbeyron, \& Helbert, 2014). A recent crystal structure of an endo-4S-L-carrageenan sulfatase from Pseudoalteromas sp. PS47 indicated that the sulfate group of the D-galactosyl-2-sulfate is important in recognition, which is also supported by the specificity provided by the identified sulfatases (Hettle et al., 2018). Recently, the carrageenan catabolism has been solved by Ficko-Blean et al. (2017) and a formylglycine-dependent tcarrageenan sulfatase, the cgsC from Zobellia galactanivorans, has been discovered. This sulfatase is specific for the $\alpha$-carrabiose motifs and removes the 2 - linked sulfate group from the 3,6-anhydrogalactosyls to generate $\beta$-carrabiose motifs (Ficko-Blean et al., 2017). Several other putative sulfatases have 
been predicted through various genome sequencing programs but the precise functions and substrate specificity remain to be determined by experimental data.

614

Sulfurylases

The use of sulfurylases, the enzymes involved in the biosynthesis of carrageenans, could be an alternative to alkali treatment in the production of carrageenans. Such enzyme treatments could be used to produce carrageenan products with enhanced gelling properties for high-value uses, such as in pharma as tablet coatings, in drug delivery, and to substitute animal fats in new products and functional foods. In red seaweeds in vivo the conversion of sulfated galactose moieties into anhydrogalactose is catalyzed by galactose-6-sulfurylases, as described above. Sulfurylase activity has been demonstrated from various seaweed extracts (Hemmingson et al., 1996; Rees, 1961; Wong \& Craigie, 1978) and Genicot-Joncour et al. (2009) have purified two enzymes, sulfurylase I and sulfurylase II, from the red seaweed Chondrus crispus, and shown that they each catalyze the conversion of v-carrageenan to l-carrageenan. Notably, sulfurylase II was shown to release sulfate during incubation with carrageenans, and this release was correlated with an increase in 3,6-anhydrogalactosyl content and viscosity increase (Genicot-Joncour et al., 2009). Subsequently, using sequence analysis (Collén et al., 2013), the genome of C. crispus was shown to contain 11 genes encoding putative galactose-6-sulfurylases, including the sulfurylase I and II characterized by Genicot-Joncour et al. (2009). The functions of these genes have not yet been validated experimentally due to difficulties in obtaining recombinant sulfurylases. Similarly, Wang et al. (2014) have identified a sulfurylase that converts $\mu$-carrageenan into $\mathrm{k}$-carrageenan from the marine algae Betaphycus gelatinus, but to the best of our knowledge this enzyme has not yet been produced recombinantly (Wang et al., 2014).

\section{Enzymatic modification of agar}

Agarases

Agarases are classified into $\alpha$-agarase (E.C. 3.2.1.158) and $\beta$-agarase (E.C. 3.2.1.81) according to their cleavage pattern, yet both belong to family GH16. $\alpha$-agarase catalyzes cleavage of the $\alpha-1,3$ linkages to produce agaro-oligosaccharides, while $\beta$-agarases cleave $\beta-1,4$ linkages to produce neoagarooligosaccharides. Agarases have been isolated from many different genera of marine bacteria, marine sediments, and other environments.

Two $\alpha$-agarases, one each from Alteromonas agarlytica GGJ1B and Thalassomonas sp. JAMB-A33, have been identified and shown to be endo-type agarases with DP4's as their main end-products (Ohta et al., 2005; Potin, Richard, Rochas, \& Kloareg, 1993). The $\alpha$-agarase from A. agarlytica (AgaA) has been cloned and sequenced and shown to be unrelated to $\beta$-agarases (and also carrageenases) and is classified as a 
644

645

646

647

648

649

650

651

652

653

654

655

656

657

658

659

660

661

662

663

664

665

666

667

668

669

670

671

672

673

674

675

GH96 family glycoside hydrolases in the CAZy-database. The AgaA33 $\alpha$-agarase from Thalassomonas sp. JAMB-A33 (now renamed to Thalassotalea agarivorans JAMBA33) has similarly been sequenced and produced recombinantly and also shown to be part of the GH96 and to hydrolyse both the $\alpha-1,3$ linkages in agarose and in porphyran (Hatada, Ohta, \& Horikoshi, 2006). $\alpha$-neoagarobiose hydrolases responsible for the production of monomers produced from DP2s have been identified from S. degradans, $Z$. galactanivorans and B. plebius and belong to family GH117 (Fu \& Kim, 2010).

Several $\beta$-agarases have been reported that cleave the internal $\beta-1,4$ linkages in agar to result in DP2s to DP8s as end products. However, most of the reported endolytic $\beta$-agarases belong to the GH16 family and like the $\mathrm{k}$-carrageenases, including the bacterial $\beta$-agarases from Aquimarina agarilytica ZC1, Celluphaga omnivescoria W5C, Flammeovirga sp., Z. galactanivorans, Pseudomonas sp. W7 and Vibrio sp. PO-303, yield DP4s as their main products, although some neoagarohexaose was also obtained as end product in several cases (product analysis often done by TLC only) (Chen, Lin, Jin, Zeng, \& Lin, 2019; Fu \& Kim, 2010; Lin, Liu, Lu, Zhao, \& Hu, 2017; Ramos, Valdehuesa, Nisola, Le, \& Chung, 2018). The same appears to be the case for the $\beta$-agarase cloned from environmental DNA obtained from mangrove sediments ( $D i, Q u, \&$ Zeng, 2018).

The conserved domain of agarases in the GH16 family has been well studied. In the characterized GH16 enzymes, the location of the GH16 module is directly adjacent to the signal peptide and the CBM6 module is in the C-terminal (Dong, Tamaru, \& Araki, 2007). The crystal structure of the catalytic domain of a GH16 $\beta$-agarase from the marine bacterium Microbulbifer thermotolerans JAMB-A94 shows a $\beta$-jelly roll composed of two antiparallel $\beta$-sheets, with open and extended substrate binding clefts, which proceeds with a molecular mechanism leading to overall retention of the anomeric configuration, similar to that reported for $\beta$-agarase from Z. galactanivorans, and the GH16 k-carrageenases (Takagi et al., 2015). The GH16 $\beta$-agarase PdAgaC from the marine bacterium Persicobacter sp. CCB-QB2 is one of only a handful of endo-acting GH16 $\beta$-agarases able to degrade agar completely to produce DP2s. The crystal structure of the PdAgaC reveals that the catalytic domain is made up of a typical $\beta$-jelly roll fold with two additional insertions and a well-conserved but wider substrate-binding cleft with some minor changes in comparison to the Z. galactanivorans $\beta$-agarases (Hafizah, Teh, \& Furusawa, 2019). Other GH16 $\beta$-agarases that produce DP2s include rAgaA from Vibrio sp. PO303 and rAgaB from Z. galactanivorans (Fu \& Kim, 2010). Agarivorans albus is also listed in the CAZY-database as the microbial origin of a GH16 $\beta$-agarase. An exo- $\beta$ agarase from Vibrio sp. JT0107 belonging to the GH50 family was characterized that can degrade not only agarose but also DP4s to DP2s (Sugano, Matsumoto, Kodama, \& Noma, 1993). Another $\beta$-agarase belonging to the GH50 family is the $\beta$-agarase from Agarivorans sp. JA-1, showing $98.8 \%$ sequence similarity to the former, and also this $\beta$-agarase produces DP2s (D. G. Lee et al., 2006). A crystal structure of a GH50 $\beta$ - 
agarase, the Aga50D from the marine microbe Saccharophagus degradans, elaborated by Pluvinage et al. (2013), reveals a $(\beta / \alpha)_{8}$-barrel fold that is elaborated with a $\beta$-sandwich domain. Enzyme-substrate complexes suggested a catalytic machinery that is most consistent with a retaining catalytic mechanism and a tunnel-shaped active site, suggesting an exo-processive mechanism (Pluvinage, Hehemann, \& Boraston, 2013). The first characterization and sequencing of family GH86 $\beta$-agarases was the AgaO from Microbulbifer-like JAMB-A94, which was characterized to be an endo-type $\beta$-agarase degrading agarose and oligo-agarans to DP6s. Likewise, a $\beta$-agarase from Vibrio sp. PO-303 has been identified and shown to produce DP8's as its main product. Other GH86 $\beta$-agarases include the Aga86C and Aga86E from Saccharophagus degradans $2-40$, but to the extent of our knowledge these agarases have been identified only by genome analysis (Fu \& Kim, 2010). Lastly, a $\beta$-agarase derived from Pseudoalteromanas sp. CY24 has been cloned and characterized. Analyses show that this enzyme degrades agar to produce DP8s and DP10s with an inversion of the anomeric configuration, in contrast to other known agarases that are retaining enzymes. The agarase from Pseudoalteromanas sp. CY24 have no known sequence similarity with any known proteins (Ma et al., 2007).

\section{Sulfatases}

Compared to carrageenans, agar normally has very few or no sulfate ester modifications such as are normally present on agaropectin or porphyran, the precursors of agar (Usov \& Zelinsky, 2013). Enzymatic hydrolysis of the sulfate groups in agaropectin (Fig. 1) could be used to simplify the process of agarose preparation because incorporation of sulfates in agarose causes weakened gel strength as a result of avoidance of cross-links during gel-formation.

Sulfatases responsible for sulfate removal in agar originating from Marinomonas sp. FW-1, $P$. carrageenovora, Thermotoga maritima and Sphingomonas sp. AS6330 have for example been shown to be able to release sulfates following incubation on agar, and the sulfatases from Marinomonas, $P$. carrageenovora and Sphingomonas have even been shown to double the gel strength of agar following enzymatic reaction (Byun et al., 2004; Lim et al., 2004; Wang, Duan, \& Fu, 2016). The agar sulfatases in the literature are normally referred to as arylsulfatases, which refers to action on 4-methylumbelliferyl sulfate or on the aromatic sulfate ester p-nitrophenyl sulfate that are used as standard substrates for activity detection, though the described enzymes are still Type I sulfurylases. The $P$. carrageenovora arylsulfatase (EC 3.1.6.1) displays homology to type III sulfurylases of the metallo- $\beta$-lactamase superfamily, though (Barbeyron et al., 2016). Since selective enzymatic desulfation with arylsulfatase can improve agar gelation, notably the arylsulfatase from $P$. carrageenovora has been investigated recently: The enzyme has been recombinantly expressed in $E$. coli and engineered by single amino acid substitution to exhibit improved 
thermostability (using error-prone PCR) (Zhu, Yin, Liu, Li, Chen, Li, Xiao, \& Ni, 2019). Another mutant of the enzyme was found to have $33 \%$ improved enzyme activity at $55^{\circ} \mathrm{C}, \mathrm{pH} 8$ (Zhu, Liang, Li, Ni, Li, Li, \& Jiang, 2020). Sulfatase activities from several other bacteria have been observed but no information is available on the mechanism and substrate specificity of the agar-sulfatases, but sequencing programs have lately revealed new hydrocolloid sulfatases which may have potential to drive future functional characterization studies.

\section{Enzymatic modifications of alginate}

Alginate Lyases

Alginate oligosaccharides, produced by alginate lyase reaction on alginate, have long been known to promote plant growth and exhibit bioactivity as antitumor agents (Wong, Preston, \& Schiller, 2000). More recently, interest in using brown macroalgae for bioenergy and biorefining processes has sparked renewed interest in alginate lyase discovery and characterization.

Alginate lyases (EC 4.2.2.-) catalyze depolymerization of alginates via a $\beta$-elimination reaction and are divided into G-block specific (EC 4.2.2.11) and M-block specific (EC 4.2.2.3) enzymes depending on the reaction they catalyze, though several of the alginate lyases appear to have activity towards both $\mathrm{G}$ - and $\mathrm{M}$ blocks in alginate, albeit acting with higher rate on either poly-mannuronate or poly-guluronate (Manns et al., 2016). Alginate lyases are produced by different bacteria, fungi, and seaweeds, and categorized in many different polysaccharide lyase families, PL5, PL6, PL7, PL14, PL15, PL17, and PL18. Substrate specificities and modes of action of the alginate lyases vary between families and family diversity implies that alginate lyases are structurally diverse. Most bacterial endolytic alginate lyases belong to family PL5 or PL7, while the most exolytic alginate lyases are assigned to family PL15 or PL17. The lyases isolated from marine mollusks and viruses are grouped in the PL14 family (Zhu \& Yin, 2015). The polysaccharide lyase families PL5, PL15, and PL17 have been found to have an $(\alpha / \alpha)$ n toroid fold structure, PL6 has a $\beta$-helix fold structure, while PL7, PL14 and PL18 are folded as $\beta$-jelly rolls and have been extensively reviewed by Garron and Cygler (2014). Most examples of characterized enzymes come from family PL7, where G-, M-, and MG-specific alginate lyases have been reported from various different organisms (Garron \& Cygler, 2014).

Recently, we discovered that the marine fungus Paradendryphiella salina encodes three putative PL7 alginate lyases, and that one of these enzymes has particular affinity for M-block degradation (Pilgaard et al., 2019). An endo-lytic PL7 alginate lyase with similar polymannuronate preference has also been identified from Flavobacterium sp. albeit this enzyme also had moderate activity towards polyguluronic acid (Inoue et al., 2014; Manns et al., 2016). Another PL7 alginate lyase from a Flavobacterium sp. with 
preferred activity on polygulurunate over polymannuronate has recently been characterized: the alginate degradation products obtained with this enzyme were DP5s, DP6s, and DP7s (Huang et al., 2013). Sphingomonas species A1 encodes several alginate lyases, A1-I, A1-II, A1-III, and A1-IV, with the A1-III being the first PL5 alginate lyase with a resolved structure. This PL5 A1-III alginate lyase acts primarily on polymannuronic acids with DP4s as the minimum substrate and produces DP2s and DP3s and also catalyzes depolymerization of acetylated alginates produced by bacteria. In contrast, the Sphingomonas derived PL7 A1-II enzyme has higher propensity for poly-guluronate than for poly-mannuronate (Manns et al., 2016). The AlyGC, a PL6 alginate lyase from the marine bacterium Glaciecola chathamensis has been characterized and also shows preference towards polyguluronic-acid blocks in alginate (Xu et al., 2017). The alginate lyase vAL-1 from Chorella virus shows two pH-dependent modes of action, endo and exo, to release DP6s and DP2s at pH 7 and 10, respectively (Ogura et al., 2009). The Agrobacterium tumefaciens alginate lyase Atu3025, is categorized as a PL15 lyase and acts on alginate polysaccharides and oligosaccharides exolytically as does the PL17 family Alg17C from Saccharophagus degradans 2-40 (Ochiai, Yamasaki, Mikami, Hashimoto, \& Murata, 2010; Park, Jagtap, \& Nair, 2014). Finally, a bifunctional family PL18 alginate lyase from Pseudomalteromonas elyakovi has been characterized, which produces DP3s to DP8s on alginate (Ma, Chi, Li, \& Wu, 2008).

\section{C5 Epimerases}

As early as in 1969, Haug et Larsen described the first bacterial mannuronan C5-epimerase, an AlgE-type epimerase from $A$. vinelandii, which attracted attention due to its ability to increase the guluronic acid content in alginates in vitro (Haug \& Larsen, 1969). Mannuronan C-5 epimerases can thus be used to control the composition and distribution of mannuronic and guluronic acids along the alginate chain and thus be applied to produce alginates with higher gel strength or with gel strength designed to specific applications. Several AlgE-type C5-epimerases have since been identified and characterized and shown to introduce different guluronic acid distribution patterns and be expressed differentially during the cell lifecycle (Høidal, Svanem, Gimmestad, \& Valla, 2000). AlgG-Type epimerase is the other type of epimerase which has been identified in bacteria, and also the ones that are related to the bacterial AlgG-type epimerase. This epimerase is periplasmic and encoded in the alginate biosynthesis gene cluster in bacteria and results in secretion of alginates with some guluronic acid residues (Michel et al., 2010; Nyvall et al., 2003).

\section{Conclusion and Future Trends}

Recent insight into the in vivo biosynthesis and maturation of seaweed hydrocolloid carbohydrates combined with new discoveries of microbial enzymes that catalyze molecular changes and 


\section{Funding}

794 This work was funded by the Innovation Fund Denmark Grant MAB4 Macroalgae Biorefinery for Value-

depolymerisation of these polysaccharides, have provided a new foundation for targeted enzymatic tailoring of seaweed hydrocolloid functionality. These options may pave the way for new tailor-made functional hydrocolloids in functional foods and in new nutritional applications, and expand the use of hydrocolloids in low-fat and animal/meat-free products. We also anticipate that introduction of postharvest enzymatic modification of the hydrocolloids can help develop and commercially viable biorefineries using a wider range of seaweeds.

One aspect of the seaweed industry, which has not been covered in this review, is the possible use of seaweed hydrocolloids in non-food applications, e.g. in various polymer composites. A range of such potential applications have been proposed in the literature such as use of k-carrageenan in nano-composite cathodes in microbial fuel cells, agar in optoelectronic materials, and alginate in various packaging and polymer-composites, reviewed by Jumaidin et al. (2018). Likewise, for the sake of completion it should also be mentioned that only a limited proportion of the seaweed residues resulting from the hydrocolloid extraction are utilized, e.g. as organic fertilizers. However, significant research efforts are currently invested in exploring the properties and the potential of seaweed extraction residues for various non-food uses, e.g. carrageenan waste may be useful as renewable filler in eco-friendly materials (Jumaidin et al., 2017). Indeed, an expanded, advanced utilization of seaweed hydrocolloids in food, biotech, and pharma applications, including use of enzymes for functional optimization, may drive the development of new sustainable processes and products based on seaweeds.

\section{CrediT author statement}

NRK and ASM: Conceptualization. NRK: Original draft preparation. NRK: Visualization. ASM: Supervision. NRK and ASM: Writing, Reviewing, Editing. Added Products (Grant no. 5157-000003B) and The Technical University of Denmark.

\section{References}

Araki, C. (1958). Seaweed polysaccharides. Proceedings $4^{\text {th }}$ International Congress of Biochemistry, 4, 1529. Pergamon Press. 
799

800

801

802

803

804

805

806

807

808

809

810

811

812

813

814

815

816

817

818

819

820

821

822

823

824

825

826

827

828

Arltoft, D., Ipsen, R., Madsen, F., \& de Vries, J. (2007). Interactions between carrageenans and milk proteins: A microstructural and rheological study. Biomacromolecules, 8(2), 729-736. https://doi.org/10.1021/bm061099q

Arvizu-Higuera, D. L., Rodríguez-Montesinos, Y. E., Murillo-Álvarez, J. I., Muñoz-Ochoa, M., \& HernándezCarmona, G. (2008). Effect of alkali treatment time and extraction time on agar from Gracilaria vermiculophylla. Journal of Applied Phycology, 20, 3-7. https://doi.org/ 10.1007/s10811-007-9258-4

Barbeyron, T., Brillet-Guéguen, L., Carré, W., Carrière, C., Czjzek, M., Hoebeke, M., \& Michel, G. (2016). Matching the diversity of sulfated biomolecules: Creation of a classification database for sulfatases reflecting their substrate specificity. PLOS ONE, 11(10), e0164846. https://doi.org/10.1371/journal.pone.0164846

Barbeyron, T., Henrissat, B., \& Kloareg, B. (1994). The gene encoding the kappa-carrageenase of Alteromonas carrageenovora is related to $\beta-1,3-1,4$-glucanases. Gene, 139, 105-109. https://doi.org/10.1016/0378-1119(94)90531-2

Barbeyron, T., Michel, G., Potin, P., Henrissat, B., \& Kloareg, B. (2000). l-carrageenases constitute a novel family of glycoside hydrolases, unrelated to that of k-carrageenases. The Journal of Biological Chemistry, 275(45), 35499-35505. https://doi.org/10.1074/jbc.M003404200

Bhattacharyya, S., Shumard, T., Xie, H., Dodda, A., Varady, K. A., Feferman, L., Halline, A. G., Goldstein, J. L., Hanauer, S. B., \& Tobacman, J. K. (2017). A randomized trial of the effects of the no-carrageenan diet on ulcerative colitis disease activity. Nutritin and Healthy Aging, 4, 181-192. https://doi.org/10.3233/NHA-170023

Bylaite E., Ilgunaite, Z., Meyer, A.S., \& Adler-Nissen, J. (2004) Influence of $\lambda$-carrageenan on the release of systematic series of volatile flavor compounds from viscous food model systems. Journal of Agricultural and Food Chemistry, 53, 3542-3549. https://doi.org/10.1021/jf035499F6

Byun, D. S., Choi, J. S., Kim, H. R., Kim, J. H., Choi, W. C., \& Godber, J. S. (2004). Purification and characterization of arylsulfatase from Sphingomonas sp. AS6330. Applied Microbiology and Biotechnology, 63(5), 553-559. https://doi.org/10.1007/s00253-003-1463-8

Calumpong, H. P., Maypa, A. P., \& Magbanua, M. (1999). Population and alginate yield and quality assessment of four Sargassum species in Negros Island, central Philippines. Hydrobiologia, (April) 211215. https://doi.org/10.1007/978-94-011-4449-0_24

Chana, A., Tromelin, A., Andriot, I., \& Guichard, E. (2006). Flavor release from iota-carragenan matrix: 
Quantitative structure-property relationshios approach. Journal of Agricultrual and Food Chemistry, 54(10), 3679-3685. https://doi.org/10.1021/jf053192wChen, X., Lin, H., Jin, M., Zeng, R., \& Lin, M. (2019). Characterization of a novel alkaline $\beta$-agarase and its hydrolysates of agar. Food Chemistry, 295, 311-319. https://doi.org/10.1016/j.foodchem.2019.05.132

Christiansen, L., Pathiraja, D., Bech, P. K., Schultz-Johansen, M. Hennessy, R., Teze, D., Choi, I., \& Stougaard, P. (2020). A multifunctinal polysaccharide utilization gene cluster in Colwellia echini encodes enzymes for the complete degradation of $\kappa$-carrageenan, $\mathrm{l}$-carrageenan, and hybrid $\beta / \kappa$-carrageenan. Msphere, 5(1), e00792-19. https://doi.org/10.1128/mSphere.00792-19.

Ciancia, M., Noseda, M. D., Matulewicz, M. C., \& Cerezo, A. S. (1993). Alkali-modification of carrageenans: mechanism and kinetics in the kappa/iota-, mu/nu- and lambda-series. Carbohydrate Polymers, 20(2), 95-98. https://doi.org/10.1016/0144-8617(93)90083-G

Collén, J., Porcel, B., Carré, W., Ball, S. G., Chaparro, C., Tonon, T., ... Boyen, C. (2013). Genome structure and metabolic features in the red seaweed Chondrus crispus shed light on evolution of the Archaeplastida. Proceedings of the National Academy of Sciences of the United States of America, 110(13), 5247-5252. https://doi.org/10.1073/pnas.1221259110

David, S., Levi, C. S., Fahoum, L., Ungar, Y., Meyron-Holtz, E. G., Shpigelman, A., \& Lesmes, U. (2018). Revisiting the carrageenan controversy: do we really understand the digestive fate and safety of carrageenan in our foods? Food \& Function, 9(3), 1344-1352. https://doi.org/10.1039/c7fo01721a

Deniaud-Bouët, E., Kervarec, N., Michel, G., Tonon, T., Kloareg, B., \& Hervé, C. (2014). Chemical and enzymatic fractionation of cell walls from Fucales: Insights into the structure of the extracellular matrix of brown algae. Annals of Botany, 114(6), 1203-1216. https://doi.org/10.1093/aob/mcu096

Di, W., Qu, W., \& Zeng, R. (2018). Cloning, expression, and characterization of thermal-stable and pH-stable agarase from mangrove sediments. Journal of Basic Microbiology, 58, 302-309. https://doi.org/10.1002/jobm.201700696

Dong, J., Tamaru, Y., \& Araki, T. (2007). A unique $\beta$-agarase, AgaA, from a marine bacterium, Vibrio sp. strain PO-303. Applied Microbiology and Biotechnology, 74(6), 1248-1255. https://doi.org/10.1007/s00253-006-0781-z

Draget, K. I., Østgaard, K., \& Smidsrød, O. (1991). Homogeneous alginate gels: A technical approach. Carbohydrate Polymers, 14(2), 159-178. https://doi.org/10.1016/0144-8617(90)90028-Q

Feferman, L., Bhattacharyya, S., Oates, E., Haggerty, N., Wang, T., Varady, K., \& Tobacman, J. K. (2020). 
859

860

861

862

863

864

865

866

867

868

869

870

871

872

873

874

875

876

877

878

879

880

881

882

883

884

885

886

887

888

Carrageenan-free dieat shows improved glucose tolerance and insulin signaling in prediabetes: A randomized, pilot clinical trial. Journal of Diabetes Research, 2020, article ID 8267980. https://doi.org/10.1155/2020/8267980

Fernández Farrés, I., \& Norton, I. T. (2014). Formation kinetics and rheology of alginate fluid gels produced by in-situ calcium release. Food Hydrocolloids, 40, 76-84.

https://doi.org/10.1016/j.foodhyd.2014.02.005

Ficko-Blean, E., Préchoux, A., Thomas, F., Rochat, T., Larocque, R., Zhu, Y., ... Michel, G. (2017). Carrageenan catabolism is encoded by a complex regulon in marine heterotrophic bacteria. Nature Communications, 8(1), 1685. https://doi.org/10.1038/s41467-017-01832-6

Fischl, R., Bertelsen, K., Gaillard, F., Coelho, S., Michel, G., Klinger, M., ... Hervé, C. (2016). The cell-wall active mannuronan $\mathrm{C} 5$-epimerases in the model brown alga Ectocarpus: From gene context to recombinant protein. Glycobiology, 26(9), 973-983. https://doi.org/10.1093/glycob/cww040

Fu, X. T., \& Kim, S. M. (2010). Agarase: Review of major sources, categories, purification method, enzyme characteristics and applications. Marine Drugs, 8(1), 200-218. https://doi.org/10.3390/md8010200

Funami, T., Fang, Y., Noda, S., Ishihara, S., Nakauma, M., Draget, K. I., ... Phillips, G. O. (2009). Rheological properties of sodium alginate in an aqueous system during gelation in relation to supermolecular structures and $\mathrm{Ca}^{2+}$ binding. Food Hydrocolloids, 23(7), 1746-1755. https://doi.org/10.1016/j.foodhyd.2009.02.014

Garron, M. L., \& Cygler, M. (2014). Uronic polysaccharide degrading enzymes. Current Opinion in Structural Biology, 28(1), 87-95. https://doi.org/10.1016/j.sbi.2014.07.012

Genicot-Joncour, S., Poinas, A., Richard, O., Potin, P., Rudolph, B., Kloareg, B., \& Helbert, W. (2009). The cyclization of the 3,6-anhydro-galactose ring of iota-carrageenan is catalyzed by two D-galactose-2,6sulfurylases in the red alga Chondrus crispus. Plant Physiology, 151(November), 1609-1616. https://doi.org/10.1104/pp.109.144329

Genicot, S. M., Rogniaux, H., Meslet-Cladière, L., Barbeyron, T., \& Helbert, W. (2014). Discovery of a novel iota carrageenan sulfatase isolated from the marine bacterium Pseudoalteromonas carrageenovora. Frontiers in Chemistry, 2, 67. https://doi.org/10.3389/fchem.2014.00067

Grant, G. T., Morris, E. R., Rees, D. A., Smith, P. J. C., \& Thom, D. (1973). Biological interactions between polysaccharides and divalent cations: The egg-box model. FEBS Letters, 32, 195-198. https://doi.org/10.1016/0014-5793(73)80770-7 
Guibet, M., Colin, S., Barbeyron, T., Genicot, S., Kloareg, B., Michel, G., \& Helbert, W. (2007). Degradation of $\lambda$-carrageenan by Pseudoalteromonas carrageenovora $\lambda$-carrageenase: a new family of glycoside hydrolases unrelated to $\mathrm{K}$ - and l-carrageenases. Biochemical Journal, 404, 105-114. https://doi.org/10.1042//BJ20061359

Hafizah, N. F., Teh, A. H., \& Furusawa, G. (2019). Biochemical Characterization of Thermostable and Detergent-Tolerant $\beta$-Agarase, PdAgaC, from Persicobacter sp. CCB-QB2. Applied Biochemistry and Biotechnology, 187(3), 770-781. https://doi.org/10.1007/s12010-018-2849-5

Hatada, Y., Ohta, Y., \& Horikoshi, K. (2006). Hyperproduction and application of $\alpha$-agarase to enzymatic enhancement of antioxidant activity of porphyran. Journal of Agricultural and Food Chemistry, 54(26), 9895-9900. https://doi.org/10.1021/jf0613684

Haug, A., \& Larsen, B. (1969). Biosynthesis of alginate. Epimerisation of D-mannuronic to L-guluronic acid residues in the polymer chain. Biochimica et Biophysica Acta, 192, 557-559. https://doi.org/10.1016/0304-4165(69)90414-0

Hemmingson, J. A., Furneaux, R. H., \& Wong, H. (1996). In vivo conversion of 6-O-sulfo-L-galactopyranosyl residues into 3,6-anhydro-L-galactopyranosyl residues in Gracilaria chilensis Bird, McLachlan et Oliveira. Carbohydrate Research, 296, 285-292. https://doi.org/10.1016/S0008-6215(96)00247-9

Hettle, A. G., Hobbs, J. K., Pluvinage, B., Vickers, C., Abe, K., Salama-Alber, O., McGuire, B. E., Hehemann, J., Hui, J. P. M., Berrue, F., Banskota, A., Zhang, J., Bottos, E. M., Van Hamme, J., \& Boraston, A. B. (2019). Insights into the $\mathrm{k} / \mathrm{l}$-carrageenan metabolism pathway of some marine Pseudoalteromonas species. Communications Biology, 2, 474-487. https://doi.org/10.1038/s42003-019-0721-y

Hettle, A. G., Vickers, C., Robb, C. S., Liu, F., Withers, S. G., Hehemann, J., \& Boraston, A. B. (2018). The molecular basis of polysaccharide sulfatase activity and a nomenclature for catalytic subsites in this class of enzyme. Structure, 26(5), 747-758. https://doi.org/10.1016/j.str.2018.03.012

Høidal, H. K., Svanem, B. I. G., Gimmestad, M., \& Valla, S. (2000). Mannuronan C-5 epimerases and cellular differentiation of Azotobacter vinelandii. Environmental Microbiology, 2(1), 27-38. https://doi.org/10.1046/j.1462-2920.2000.00074.x

Huang, L., Zhou, J., Li, X., Peng, Q., Lu, H., \& Du, Y. (2013). Characterization of a new alginate lyase from newly isolated Flavobacterium sp. S20. Journal of Industrial Microbiology and Biotechnology, 40(1), 113-122. https://doi.org/10.1007/s10295-012-1210-1

Inoue, A., Satoh, A., Morishita, M., Tokunaga, Y., Miyakawa, T., Tanokura, M., \& Ojima, T. (2016). Functional 
heterologous expression and characterization of mannuronan C5-epimerase from the brown alga Saccharina japonica. Algal Research, 16, 282-291. https://doi.org/10.1016/j.algal.2016.03.030

Inoue, A., Takadono, K., Nishiyama, R., Tajima, K., Kobayashi, T., \& Ojima, T. (2014). Characterization of an alginate lyase, FIAlyA, from Flavobacterium sp. strain UMI-01 and its expression in Escherichia coli. Marine Drugs, 12(8), 4693-4712. https://doi.org/10.3390/md12084693

Istini, S., Ohno, M., \& Kusunose, H. (1994). Methods of analysis for agar, carrageenan and alginate in seaweed. Bulletin of Marine Science and Fisheries, (14), 49-55.

Jumaidin, R., Sapuan, S. M., Jawaid, M., Ishak, M. R. \& Sahari, J. (2017). Characteristics of Eucheuma cottonii waste from East Malaysia: physical, thermal and chemical composition. European Journal of Phycology, 52(2), 200-207. https://doi.org/10.1080/09670262.2016.1248498

Jumaidin, R., Sapuan, S. M., Jawaid, M., Ishak, M. R. \& Sahari, J. (2018). Seaweeds as renewable sources for biopolymers and its composites: A review. Current Analytical Chemistry, 14(3), 249-267.

https://doi.org/10.2174/1573411013666171009164355Kalitnik, A. A., Nedashkovskaya, O. I., Stenkova, A. M., Yermak, I. M., \& Kukhlevskiy, A. D. (2018). Carrageenanolytic enzymes from marina bacteria associated with the red alga Tichocarpus crinitus. Journal of Applied Phycology, 30, 2071-2081. https://doi.org/10.1007/s10811-017-1355-4

Kang, Z., Want, T., Li, Y., Li, K., \& Ma, H. (2020) Effect of sodium alginate on physical-chemical, protein conformation and sensory of low-fat frankfurters. Meat Science, 162, 108043. https://doi.org/10.1016/j.meatsci.2019.108043

Khalil, H. P. S. A., Lai, T. K., Tye, Y. Y., Rizal, S., Chong, E. W. N., Yap, S. W., Hamzah, A. A., Fazita, M. R. N., Paridah, M. T. (2018). A review of extractions of seaweed hydrocolloids: Properties and applications. Express Polymer Letters, 12(4), 296-317. https://doi.org/10.3144/expresspolymlett.2018.27

Lawson, C. J., \& Rees, D. (1970). An enzyme for the metabolic control of polysaccharide conformation and function. Nature, 227, 392-393. https://doi.org/10.1038/227392a0.

Lee, D. G., Park, G. T., Kim, N. Y., Lee, E. J., Jang, M. K., Shin, Y. G., ... Lee, S. H. (2006). Cloning, expression, and characterization of a glycoside hydrolase family $50 \beta$-agarase from a marine Agarivorans isolate. Biotechnology Letters, 28(23), 1925-1932. https://doi.org/10.1007/s10529-006-9171-y

Lee, W. K., Lim, Y. Y., Leow, A. T. C., Namasivayam, P., Abdullah, J. O., \& Ho, C. L. (2017). Biosynthesis of agar in red seaweeds: A review. Carbohydrate Polymers, 164, 23-30. https://doi.org/10.1016/j.carbpol.2017.01.078 
Lim, J. M., Jang, Y. H., Kim, H. R., Kim, Y. T., Choi, T. J., Kim, J. K., \& Nam, S. W. (2004). Overexpression of arylsulfatase in E. coli and its application to desulfatation of agar. Journal of Microbiology and Biotechnology, 14(4), 777-782.

Lin, B., Liu, Y., Lu, G., Zhao, M., \& Hu, Z. (2017). An agarase of glycoside hydrolase family 16 from marine bacterium Aquimarina agarilytica ZC1. FEMS Microbiology Letters, 364(4), fnx012 (1-6). https://doi.org/10.1093/femsle/fnx012

Lipinska, A. P., Collén, J., Krueger-Hadfield, S. A., Mora, T., \& Ficko-Blean, E. (2020). To gel or not to gel: differential expression of carrageenan-related genes between the gametophyte and tetasporophyte life cycle stages of the red alga Chondrus crispus. Scientific Reports, 10, 11498. https://doi.org/10.1038/s41598-020-67728-6

Lombard, V., Golaconda Ramulu, H., Drula, E., Coutinho, P. M., \& Henrissat, B. (2014). The carbohydrateactive enzymes database (CAZy) in 2013. Nucleic Acids Research, 42(D1), 490-495. https://doi.org/10.1093/nar/gkt1178

Ma, C., Lu, X., Shi, C., Li, J., Gu, Y., Ma, Y., ... Yu, W. (2007). Molecular cloning and characterization of a novel $\beta$-agarase, AgaB, from marine Pseudoalteromonas sp. CY24. Journal of Biological Chemistry, 282(6), 3747-3754. https://doi.org/10.1074/jbc.M607888200

Ma, L. Y., Chi, Z. M., Li, J., \& Wu, L. F. (2008). Overexpression of alginate lyase of Pseudoalteromonas elyakovii in Escherichia coli, purification, and characterization of the recombinant alginate lyase. World Journal of Microbiology and Biotechnology, 24(1), 89-96. https://doi.org/10.1007/s11274-007-9443-2

Manns D., Nyffenegger, C., Saake, B., \& Meyer, A. S. (2016). Impact of different alginate lyases on combined cellulase-lyase saccharification of brown seaweed. RSC Advances, 6, 45392-45401. https://doi.org/10.1039/c6ra06669k

Manuhara, G. J., Praseptiangga, D., \& Riyanto, R. A. (2016). Extraction and characterization of refined Kcarrageenan of red algae [Kappaphycus Alvarezii (Doty ex P.C. Silva, 1996)] originated from Karimun Jawa Islands. Aquatic Procedia, 7, 106-111. https://doi.org/10.1016/j.aqpro.2016.07.014

Matard-Mann, M., Bernard, T., Leroux, C., Barbeyron, T., Larocque, R., Préchoux, A., ... Czjzek, M. (2017). Structural insights into marine carbohydrate degradation by family GH16 -carrageenases. Journal of Biological Chemistry, 292(48), 19919-19934. https://doi.org/10.1074/jbc.M117.808279

Market Research (2020) Hydrocolloids Market Global Forecast 2020-2025. https://www.marketresearchengine.com/hydrocolloids-market?mod=article_inline; 
Mchugh, D. J. (2003). A guide to the seaweed industry. FAO Fisheries Technical Paper No. 441.

McLean, M. W., \& Williamson, F. B. (1979). Glycosulphatase from Pseudomonas carrageenovora. European Journal of Biochemistry, 101(2), 497-505. https://doi.org/10.1111/j.1432-1033.1979.tb19744.x

Michel, G., Chantalat, L., Duee, E., Barbeyron, T., Henrissat, B., Kloareg, B., \& Dideberg, O. (2001). The kcarrageenase of $P$. carrageenovora features a tunnel-shaped active site: A novel insight in the evolution of clan-B glycoside hydrolases. Structure, 9, 513-525. https://doi.org/10.1016/S09692126(01)00612-8

Michel, G., Chantalat, L., Fanchon, E., Henrissat, B., Kloareg, B., \& Dideberg, O. (2001). The t-carrageenase of Alteromonas fortis: A $\beta$-helix fold-containing enzyme for the degradation of a highly polyanionic polysaccharide. Journal of Biological Chemistry, 276(43), 40202-40209. https://doi.org/10.1074/jbc.M100670200

Michel, G., Tonon, T., Scornet, D., Cock, J. M., \& Kloareg, B. (2010). The cell wall polysaccharide metabolism of the brown alga Ectocarpus siliculosus. Insights into the evolution of extracellular matrix polysaccharides in Eukaryotes. New Phytologist, 188(1), 82-97. https://doi.org/10.1111/j.14698137.2010.03374.x

Moradali, M. F., Ghods, S., \& Rehm, B. H. A. (2018). Alginate biosynthesis and biotechnological production. Chpater 1 in Alginates and their biomedical appliciations (Eds. B. H. A. Rehm \& M. F. Moradali), pp. 126, Springer Series in Biomaterials Science and Engineering, Springer Nature, Singapore, Singapore.

Morris, E. R., Rees, D. A., \& Robinson, G. (1980). Cation-specific aggregation of carrageenan helices: Domain model of polymer gel structure. Journal of Molecular Biology, 138(2), 349-362. https://doi.org/10.1016/0022-2836(80)90291-0

Moses, J., Anandhakumar, R., \& Shanmugam, M. (2015). Effect of alkaline treatment on the sulfate content and quality of semi-refined carrageenan prepared from seaweed Kappaphycus alvarezii Doty (Doty) farmed in Indian waters. African Journal of Biotechnology, 14(18), 1584-1589. https://doi.org/10.5897/ajb2014.14203

Mtolera, M. S. P., \& Buriyo, A. S. (2004). Studies on Tanzanian Hypneaceae: Seasonal variation in content and quality of kappa-carrageenan from Hypnea musciformis (Gigartinales: Rhodophyta). Western Indian Ocean Journal of Marine Science, 3(1), 43-49.

Mørch, Y. A., Donati, I., Strand, B. L., \& Skjåk-Bræk, G. (2006). Effect of $\mathrm{Ca}^{2+}, \mathrm{Ba}^{2+}$, and $\mathrm{Sr}^{2+}$ on alginate microbeads. Biomacromolecules, 7(5), 1471-1480. https://doi.org/10.1021/bm060010d 
Nyvall, P., Corre, E., Boisset, C., Barbeyron, T., Rousvoal, S., Scornet, D., ... Boyen, C. (2003). Characterization of mannuronan C-5-epimerase genes from the brown alga Laminaria digitata. Plant Physiology, 133(October), 726-735. https://doi.org/10.1104/pp.103.025981

Ochiai, A., Yamasaki, M., Mikami, B., Hashimoto, W., \& Murata, K. (2010). Crystal structure of exotype alginate lyase Atu3025 from Agrobacterium tumefaciens. Journal of Biological Chemistry, 285(32), 24519-24528. https://doi.org/10.1074/jbc.M110.125450

Ogura, K., Yamasaki, M., Yamada, T., Mikami, B., Hashimoto, W., \& Murata, K. (2009). Crystal structure of family 14 polysaccharide lyase with pH-dependent modes of action. Journal of Biological Chemistry, 284(51), 35572-35579. https://doi.org/10.1074/jbc.M109.068056

Ohta, Y., Hatada, Y., Miyazaki, M., Nogi, Y., Ito, S., \& Horikoshi, K. (2005). Purification and Characterization of a novel $\alpha$-agarase from a Thalassomonas sp. Current Microbiology, 50(4), 212-216. https://doi.org/10.1007/s00284-004-4435-z

Paravisini, L., \& Guichard, E. (2017) Interactions between aroma compounds and food matrix. Chapter 9 in Flavour: From Food to Perception (Eds. E. Guichard, C. Salles, M. Morzel, \& A. Le Bon), pp. 208-234, John Wiley \& Sons Ltd, West Sussex, UK. https://doi.org/10.1002/9781118929384

Park, D., Jagtap, S., \& Nair, S. K. (2014). Structure of a PL17 family alginate lyase demonstrates functional similarities among exotype depolymerases. Journal of Biological Chemistry, 289(12), 8645-8655. https://doi.org/10.1074/jbc.M113.531111

Pereira-Pacheco, F., Robledo, D., Rodríguez-Carvajal, L., \& Freile-Pelegrín, Y. (2007). Optimization of native agar extraction from Hydropuntia cornea from Yucatán, México. Bioresource Technology, 98, 12781284. https://doi.org/10.1016/j.biortech.2006.05.016

Pereira, L., Gheda, S. F., \& Ribeiro-Claro, P. J. A. (2013). Analysis by vibrational spectroscopy of seaweed polysaccharides with potential use in food, pharmaceutical, and cosmetic industries. International Journal of Carbohydrate Chemistry, 2013(vi), 1-7. https://doi.org/10.1155/2013/537202

Pilgaard, B., Wilkens, C., Herbst, F., Vuillemin, M., Rhein-Knudsen, N., Meyer, A. S., \& Lange, L. (2019). Proteomic enzyme analysis of the marine fungus Paradendryphiella salina reveals alginate lyase as a minimal adaptation strategy for brown algae degradation. Scientific Reports, 9, 12338-12350, https://doi.org/10.1038/s41598-019-48823-9

Pluvinage, B., Hehemann, J. H., \& Boraston, A. B. (2013). Substrate recognition and hydrolysis by a family 50 exo- $\beta$-agarase, aga50D, from the marine bacterium Saccharophagus degradans. Journal of Biological 
Porse, H., \& Rudolph, B. (2017). The seaweed hydrocolloid industry: 2016 updates, requirements, and outlook. Journal of Applied Phycology, 29, 2187-2200. https://doi.org/10.1007/s10811-017-1144-0

Potin, P., Richard, C., Barbeyron, T., Henrissat, B., Gey, C., Petillot, Y., ... Kloareg, B. (1995). Processing and hydrolytic mechanism of the cgkA-encoded k-carrageenase of Alteromonas carrageenovora. European Journal of Biochemistry, 228, 971-975. https://doi.org/10.1111/j.1432-1033.1995.tb20348.x

Potin, P., Richard, C., Rochas, C., \& Kloareg, B. (1993). Purification and characterization of the $\alpha$-agar-ase from Alteromonas agarlyticus (Cataldi) comb . nov., strain GJ1B. European Journal of Biochemistry, 214, 599-607. https://doi.org/10.1111/j.1432-1033.1993.tb17959.x

Praiboon, J., Chirapart, A., Akakabe, Y., Bhumibhamon, O., \& Kajiwara, T. (2006). Physical and Chemical Characterization of agar polysaccharides extracted from the Thai and Japanese species of Gracilaria. ScienceAsia, 32(1), 11-17. https://doi.org/10.2306/scienceasia1513-1874.2006.32(s1).011

Préchoux, A., Genicot, S., Rogniaux, H., \& Helbert, W. (2016). Enzyme-assisted preparation of furcellaran-like 1055

Préchoux, A., Genicot, S., Rogniaux, H., \& Helbert, W. (2013). Controlling carrageenan structure using a novel formylglycine-dependent sulfatase, an endo-4S-iota-carrageenan sulfatase. Marine Biotechnology, 15, 265-274. https://doi.org/10.1007/s10126-012-9483-y k-/ß-carrageenan. Marine Biotechnology, 18, 133-143. https://doi.org/10.1007/s10126-015-9675-3

Qin, X., Ma, C., Lou, Z., \& Wang, H. (2015). Effects of additives on the lyophilized and thermal stability of dgalactose-6-sulfurylase activity from Eucheuma striatum (Rhodophyta). Journal of Applied Phycology, 27(4), 1709-1715. https://doi.org/10.1007/s10811-014-0466-4

Ramos, K. R. M., Valdehuesa, K. N. G., Nisola, G. M., Lee, W., \& Chung, W. (2018). Identification and characterization of a thermostable endolytic $\beta$-agarase Aga 2 from a newly isolated marine agarolytic bacteria Cellulophaga omnivescoria W5C. New Biotechnology, 40, 261-267. http://dx.doi.org/10.1016/j.nbt.2017.09.006

Rees, D. A. (1961). Enzymic synthesis of 3:6-anhydro-I-galactose within porphyran from I-galactose 6sulphate units. The Biochemical Journal, 81, 347-352. https://doi.org/10.1042/bj0810347

Rees, D. A. (1961). Enzymic desulphation of porphyran. The Biochemical Journal, 80(3), 449-453. https://doi.org/10.1042/bj0800449

Rhein-Knudsen, N., Ale, M. T., Ajalloueian, F., \& Meyer, A. S. (2017). Characterization of alginates from 
Ghanaian brown seaweeds: Sargassum spp. and Padina spp. Food Hydrocolloids, 71, 236-244. https://doi.org/10.1016/j.foodhyd.2017.05.016

Rhein-Knudsen, N., Ale, M. T., Ajalloueian, F., Yu, L., \& Meyer, A. S. (2017). Rheological properties of agar and carrageenan from Ghanaian red seaweeds. Food Hydrocolloids, 63, 50-58. https://doi.org/10.1016/j.foodhyd.2016.08.023

Rhein-Knudsen, N., Ale, M. T., \& Meyer, A. S. (2015). Seaweed hydrocolloid production: An update on enzyme assisted extraction and modification technologies. Marine Drugs, 13(6), 3340-3359. https://doi.org/10.3390/md13063340

Rinaudo, M., Karimian, A., \& Milas, M. (1979). Polyelectrolyte behavior of carrageenans in aqueous solutions. Biopolymers, 18(7), 1673-1683. https://doi.org/10.1002/bip.1979.360180707

Rodríguez, M. C., Matulewicz, M. C., Noseda, M. D., Ducatti, D. R. B., \& Leonardi, P. I. (2009). Agar from Gracilaria gracilis (Gracilariales, Rhodophyta) of the Patagonic coast of Argentina - Content, structure and physical properties. Bioresource Technology, 100(3), 1435-1441. https://doi.org/10.1016/j.biortech.2008.08.025

Schefer, L., Adamcik, J., \& Mezzenga, R. (2014). Unravelling secondary structure changes on individual anionic polysaccharide chains by atomic force microscopy. Angewandte Chemie - International Edition, 53(21), 5376-5379. https://doi.org/10.1002/anie.201402855

Shen, J., Chang, Y., Chen, F., \& Dong, S. (2018). Expression and characterization of a k-carrageenase from marine bacterium Wenyingzhuangia aestuarii OF219: A biotechnological tool for the depolymerization of K-carrageenan. Interantional Journal of Biological Macromolecules, 112, 93-100. https://doi.org/10.1016/j.ijbiomac.2018.01.075

Shukla, M. K., Kumar, M., Prasad, K., Reddy, C. R. K., \& Jha, B. (2011). Partial characterization of sulfohydrolase from Gracilaria dura and evaluation of its potential application in improvement of the agar quality. Carbohydrate Polymers, 85(1), 157-163. https://doi.org/10.1016/j.carbpol.2011.02.009

Souza, B. W. S., Cerqueira, M. A., Bourbon, A. I., Pinheiro, A. C., Martins, J. T., Teixeira, J. A., ... Vicente, A. A. (2012). Chemical characterization and antioxidant activity of sulfated polysaccharide from the red seaweed Gracilaria birdiae. Food Hydrocolloids, 27(2), 287-292. https://doi.org/10.1016/j.foodhyd.2011.10.005

Sugano, Y., Matsumoto, T., Kodama, H., \& Noma, M. (1993). Cloning and sequencing of agaA, a unique agarase 0107 gene from a marine bacterium, Vibrio sp. strain JT0107. Applied and Environmental 
Takagi, E., Hatada, Y., Akita, M., Ohta, Y., Yokoi, G., Miyazaki, T., ... Tonozuka, T. (2015). Crystal structure of the catalytic domain of a GH16 $\beta$-agarase from a deep-sea bacterium, Microbulbifer thermotolerans JAMB-A94. Bioscience, Biotechnology and Biochemistry, 79(4), 625-632. https://doi.org/10.1080/09168451.2014.988680

Tako, M., \& Nakamura, S. (1988). Gelation mechanism of agarose. Carbohydrate Research, 180(2), 277-284. https://doi.org/10.1016/0008-6215(88)80084-3

Tako, M., Tamaki, Y., Teruya, T., \& Takeda, Y. (2014). The Principles of starch gelatinization and retrogradation. Food and Nutritional Sciences, 5, 280-291. https://doi.org/10.4236/fns.2014.53035

Tecante, A., \& Núñez, C. (2012). Solution properties of k-carrageenan and its interaction with other polysaccharides in aqueous media. Chapter 10 in: Rheology, (De Vicente J., ed), pp. 241-264, IntechOpen, Rijeka, Croatia.

Thrimawithana, T. R., Young, S., Dunstan, D. E., \& Alany, R. G. (2010). Texture and rheological characterization of kappa and iota carrageenan in the presence of counter ions. Carbohydrate Polymers, 82(1), 69-77. https://doi.org/10.1016/j.carbpol.2010.04.024

Torres, M. R., Sousa, A. P. A., Silva Filho, E. A. T., Melo, D. F., Feitosa, J. P. A., de Paula, R. C. M., \& Lima, M. G. S. (2007). Extraction and physicochemical characterization of Sargassum vulgare alginate from Brazil. Carbohydrate Research, 342(14), 2067-2074. https://doi.org/10.1016/j.carres.2007.05.022

Usov, A. I., \& Zelinsky, N. D. (2013). Chemical structures of algal polysaccharides. In Functional ingredients from algae for foods and nutraceuticals. Chapter 2, pp. 23-84, Woodhead Publishing Ltd., Sawston, Cambridge, UK. https://doi.org/10.1533/9780857098689.1.23

Van de Velde, F., Knutsen, S. H., Usov, A. I., Rollema, H. S., \& Cerezo, A. S. (2002). ${ }^{1} \mathrm{H}$ and ${ }^{13} \mathrm{C}$ high resolution NMR spectroscopy of carrageenans: application in research and industry. Trends in Food Science \& Technology, 13, 73-92. https://doi.org/10.1016/S0924-2244(02)00066-3

Wang, A., Islam, M. N., Qin, X., Wang, H., Peng, Y., \& Ma, C. (2014). Purification, identification, and characterization of d-galactose-6-sulfurylase from marine algae (Betaphycus gelatinus). Carbohydrate Research, 388, 94-99. https://doi.org/10.1016/j.carres.2013.12.010

Weigl, J., \& Yaphe, W. (1966). Glycosulfatase of Pseudomonas carrageenovora: Desulfation of disaccharide from k-carrageenan. Canadian Journal of Microbiology, 12(4), 874-876. https://doi.org/10.1139/m66- 
118

Williams, S. J., Denehy, E., \& Krenske, E. H. (2014). Experimental and theoretical insights into the mechanisms of sulfate and sulfamate ester hydrolysis and the end products of type i sulfatase inactivation by aryl sulfamates. Journal of Organic Chemistry, 79(5), 1995-2005. https://doi.org/10.1021/jo4026513

Wang, X., Duan, D., \& Fu, X. (2016). Enzymatic desulfatation of the red seaweeds agar by Marinomonas arylsulfatase. International Journal of Biological Macromolecules, 93, 600-608. http://dx.doi.org/10.1016/j.ijbiomac.2016.08.031

Wong, K. F., \& Craigie, J. S. (1978). Sulfohydrolase Activity and Carrageenan Biosynthesis in Chondrus crispus (Rhodophyceae). Plant Physiology, 61(1978), 663-666. https://doi.org/10.1104/pp.61.4.663

Wong, T. Y., Preston, L. A., \& Schiller, N. L. (2000). Alginate Lyase: Review of Major Sources and Enzyme Characteristics, Structure-Function Analysis, Biological Roles, and Applications. Annual Review of Microbiology, 54(1), 289-340. https://doi.org/10.1146/annurev.micro.54.1.289

Wu, P., \& Imai, M. (2012). Novel Biopolymer Composite Membrane Involved with Selective Mass Transfer and Excellent Water Permeability. Advancing Desalination, 57-81. https://doi.org/10.5772/50697

Xiao, A., Zeng, J., Li, J., Zhu, Y., Xiao, Q., \& Ni, H. (2018). Molecular cloning, characterization, and heterologous expression of a new $\mathrm{K}$-carrageenase gene from Pseudoalteromonas carrageenovora ASY5. Journal of Food Biochemistry, 42, e12677. https://doi.org/10.1111/jfbc.12677

Xu, F., Dong, F., Wang, P., Cao, H. Y., Li, C. Y., Li, P. Y., ... Chen, X. L. (2017). Novel molecular insights into the catalytic mechanism of marine bacterial alginate lyase AlyGC from polysaccharide lyase family 6. Journal of Biological Chemistry, 292(11), 4457-4468. https://doi.org/10.1074/jbc.M116.766030

Yuguchi, Y., Thu Thuy, T. T., Urakawa, H., \& Kajiwara, K. (2002). Structural characteristics of carrageenan gels: Temperature and concentration dependence. Food Hydrocolloids, 16(6), 515-522. https://doi.org/10.1016/S0268-005X(01)00131-X

Zhao, Y., Li, F., Carvajal, M. T., \& Harris, M. T. (2009). Interactions between bovine serum albumin and alginate: An evaluation of alginate as protein carrier. Journal of Colloid and Interface Science, 332(2), 345-353. https://doi.org/10.1016/j.jcis.2008.12.048

Zhu, B., \& Yin, H. (2015). Alginate lyase: Review of major sources and classification, properties, structurefunction analysis and applications. Bioengineered, 6(3), 125-131. 
https://doi.org/10.1080/21655979.2015.1030543

1157 Zhu, Y., Liang, M., Li, H., Ni, H., Li, L., Li, Q., \& Jiang, Z. (2020). A mutant of Pseudoalteromonas carrageenovora arylsulfatase with enhanced enzyme activity and its potential application in improvement of the agar quality. Food Chemistry, 320, 126652. https://doi.org/10.1016/j.foodchem.2020.126652.

1161 Zhu, Y., Yin, X., Liu, H., Li, H., Chen, Y., Li, L., Xiao, A., \& Ni, H. (2019). Substitution of His260 residue alters the thermostability of Pseudoalteromonas carrageenovora arylsulfatase. Acta Oceanologica Sinica, 38(6), 75-82. https://doi.org/10.1007/s13131-019-1356-z

1164 Zinoun, M., Diouris, M., Potin, P., Floch, J. Y., \& Deslandes, E. (1997). Evidence of sulfohydrolase activity in 1165 the red alga Calliblepharis jubata. Botanica Marina, 40, 49-53. 
Highlights

- Chemical structures of seaweed-derived hydrocolloids carrageenans, agar, alginate

- Illustrated gelation mechanisms of seaweed-derived hydrocolloids

- Update of biosynthesis of cell wall hydrocolloid carbohydrates in seaweeds

- New microbial enzymes that catalyze modifications of carrageenans, agar, alginate 